\title{
Elevated Mixed Layers and Associated Severe Thunderstorm Environments in South and North America
}

\author{
BRUNO Z. RIBEIRO \\ Centro de Previsão de Tempo e Estudos Climáticos, Instituto Nacional de Pesquisas Espaciais, Cachoeira Paulista, São Paulo, Brazil \\ LANCE F. BOSART \\ Department of Atmospheric and Environmental Sciences, University at Albany, State University of New York, Albany, New York
}

(Manuscript received 2 May 2017, in final form 27 September 2017)

\begin{abstract}
This study presents a climatological and composite analysis of elevated mixed layers (EMLs) in South and North America derived from the NCEP Climate Forecast System Reanalysis. The EMLs are identified based on objective criteria applied to the reanalysis data. Composite analyses of synoptic-scale conditions and severe weather parameters associated with spring EML cases are presented. EMLs are more frequent immediately to the east of the Andes and the Rockies. The North American EMLs form by surface heating over the higher terrain of the Rockies, with peak frequency occurring in spring and summer. EMLs in South America are generated by differential temperature advection due to ageostrophic circulations east of the Andes, as indicated by the temperature lapse rate tendency equation, which relates to the higher frequency of EMLs during the cold season in South America. EMLs over North America are about $100 \mathrm{hPa}$ lower than over South America due to the lower height of the Rockies in comparison to the Andes. The synoptic conditions associated with EMLs in South and North America are characterized by an upper-level trough upstream and lowlevel moisture flux convergence due to poleward-directed flow, favoring synoptic-scale ascent poleward of the EML location, where the convective inhibition is relatively low. When EMLs occur, higher surface-based convective available potential energy and low-level storm-relative helicity, in association with lower lifting condensation level heights observed in North America, indicate that surface-based supercell storms and tornadoes are more likely to occur on this continent in comparison with South America, corroborating observations.
\end{abstract}

\section{Introduction}

Elevated mixed layers (EMLs) are layers of constant vertical distribution of potential temperature $\theta$, that is, layers having dry-adiabatic temperature lapse rates, not coupled to the ground (Carlson and Ludlam 1968; Lanicci and Warner 1991a, hereafter LW91). These layers occur mainly to the east (downstream) of great mountain ranges, a result of horizontal advection of surface-heated air over higher terrain and/or ageostrophic circulations in the lee of the mountains. The Rockies in North America (NA; e.g., Carlson and Ludlam 1968; Banacos and Ekster 2010, hereafter BE10) and the Tibetan Plateau in East Asia (e.g., Das et al. 2014) are known to favor the formation of EMLs that can have a great impact on the

Corresponding author: Bruno Z. Ribeiro, bruno.ribeiro@cptec. inpe.br atmospheric conditions over the lower terrain downstream due to their association with hazardous weather events (Cordeira et al. 2017). Observations and case studies by Rasmussen and Houze (2016) show EMLs occur east of the Andes in South America (SA). The purpose of this paper is to document SA EMLs and to compare and contrast their formation processes with NA EMLs.

A complete climatology of NA EMLs was done by LW91 and Lanicci and Warner $(1991 b, c)$ in three sequential papers. They used observed NA soundings from 1983 to 1986 and applied several criteria to automatically search for EMLs. The classic model of EML formation depicts an approaching trough in the mid- and upper troposphere and associated southwesterly flow over the high terrain in northern Mexico/southwestern United States. This southwesterly flow advects a dry, mixed air mass from over higher terrain eastward over somewhat less warm but much more moist planetary 
boundary layer (PBL) air at lower elevations over the Great Plains. This setup can create an environment of high potential instability over the Great Plains and is often observed from spring to summer, when solar radiation is strong enough to form deep, surface-based mixed PBLs over the Rockies.

The mechanisms for EML formation and maintenance in NA were investigated by BE10. The authors presented an equation for the local tendency of temperature lapse rate $(\gamma ; \gamma \equiv-d T / d z$, where $T$ is temperature and $z$ is height). The local $\gamma$ tendency is given by

$$
\begin{aligned}
& \frac{\partial \gamma}{\partial t}=-\underbrace{\frac{1}{c_{p}} \frac{\partial Q}{\partial z}}_{\mathrm{A}} \underbrace{-\mathbf{V} \cdot \nabla_{h} \gamma}_{\mathrm{B}} \underbrace{-w \frac{\partial \gamma}{\partial z}}_{\mathrm{C}} \\
& +\underbrace{\frac{\partial \mathbf{V}}{\partial z} \cdot \nabla_{h} T}_{\mathrm{D}}+\underbrace{\frac{\partial w}{\partial z}\left(\Gamma_{d}-\gamma\right)}_{\mathrm{E}},
\end{aligned}
$$

where $Q$ is the diabatic heating rate, $\mathbf{V}$ is the horizontal wind vector, $w$ is the vertical velocity, $c_{p}$ is the specific heat of dry air at constant pressure, and $\Gamma_{d}$ is the dryadiabatic temperature lapse rate. Term $\mathrm{A}$ is the differential diabatic heating rate; terms $\mathrm{B}$ and $\mathrm{C}$ are the horizontal and vertical $\gamma$ advection, respectively; term $\mathrm{D}$ is the differential horizontal temperature advection (associated with the ageostrophic wind because the differential horizontal temperature advection by the geostrophic wind is zero); and term $\mathrm{E}$ is the stretching term. The scale analysis performed by BE10 showed that the horizontal advection of $\gamma$ is one to two orders of magnitude greater than the other terms and corroborates previous studies of EMLs in NA (Carlson and Ludlam 1968; LW91). This equation will be used to analyze the physical processes associated with EMLs east of the Andes and the Rockies, respectively.

Severe thunderstorms occur in thermodynamically unstable environments where the vertical wind shear is high and there is sufficient lifting capable to trigger convection and release the thermodynamic instability (Thompson et al. 2003; Brooks et al. 2003). In this context, EMLs are known to be associated with severe thunderstorms (e.g., Carlson and Ludlam 1968; LW91; Lanicci and Warner 1991c; BE10; Cordeira et al. 2017). The concomitant occurrence of moderate convective inhibition (CIN) caused by the temperature inversion in the base of the EML, high convective available potential energy (CAPE) associated with steep $\gamma$ in the EML over a warm/moist PBL, and sufficient vertical wind shear are recognized to favor severe thunderstorms in NA. Despite being an important feature, the EML is not a sufficient ingredient for severe thunderstorm formation (Cordeira et al. 2017) and can prevent convective initiation in some cases (Carlson and
Ludlam 1968). In SA, the EMLs' influences on severe thunderstorm environments are likely similar to NA.

Brooks et al. (2003) have shown that southeastern SA, despite being a hot spot for severe thunderstorms in the world (Velasco and Fritsch 1987; Zipser et al. 2006), has a lower frequency of "tornado environments" than NA. Both Americas have a vast amount of land east of the mountain ranges, but there are several geographical characteristics that contribute to their different severe thunderstorm climatologies. One of the main differences is the moisture source: the Gulf of Mexico in NA compared to the Amazon basin in SA. The Amazon is dry in the cold season of the Southern Hemisphere, whereas the Gulf of Mexico remains warm and, consequently, moist, throughout the cold season in the Northern Hemisphere. Agricultural lands can also contribute to the moisture budget through evapotranspiration processes. Another important feature is the shape of the mountain ranges: both have north-south orientation in the subtropical and extratropical latitudes, but in general, the Rockies are longitudinally wider, whereas the Andes are higher and have steeper slopes (Fig. 1). The Andes form a higher barrier to the low- to midtropospheric flow, while the broader Rockies act as an elevated heat source, mainly in the warm season, because of their flatter shape. All of these characteristics likely influence severe thunderstorm environments to the east of the mountains.

In this paper, an objective methodology to identify EMLs was used to build a climatology of EMLs in SA and NA. The characteristics of EMLs in both continents and the synoptic environments related to their occurrence were analyzed. The scientific questions that arise in this research are as follows: How often and where do EMLs occur in SA east of the Andes? How do the EML climatologies over SA and NA compare? What are the differences in characteristics of the EMLs, such as thickness and base height? What is the influence of EMLs in the severe weather environments in SA that might explain the meteorological differences between both continents?

This study is the first to quantify EML occurrence east of the Andes and the associated synoptic-scale environments, addressing the above questions. It is currently unknown what the characteristics of SA EMLs are, as well as their potential influence on observed convection in SA, and whether or not any similarities can be drawn with NA EMLs.

The paper is organized as follows: section 2 presents data and methodology; section 3 shows the results, divided into characteristics of EMLs in both continents (section 3a) and the composites of EML cases over the regions (section $3 \mathrm{~b}$ ), along with discussions of the main findings; and, in section 4, a synthesis of the paper results is shown and the conclusions are discussed. 

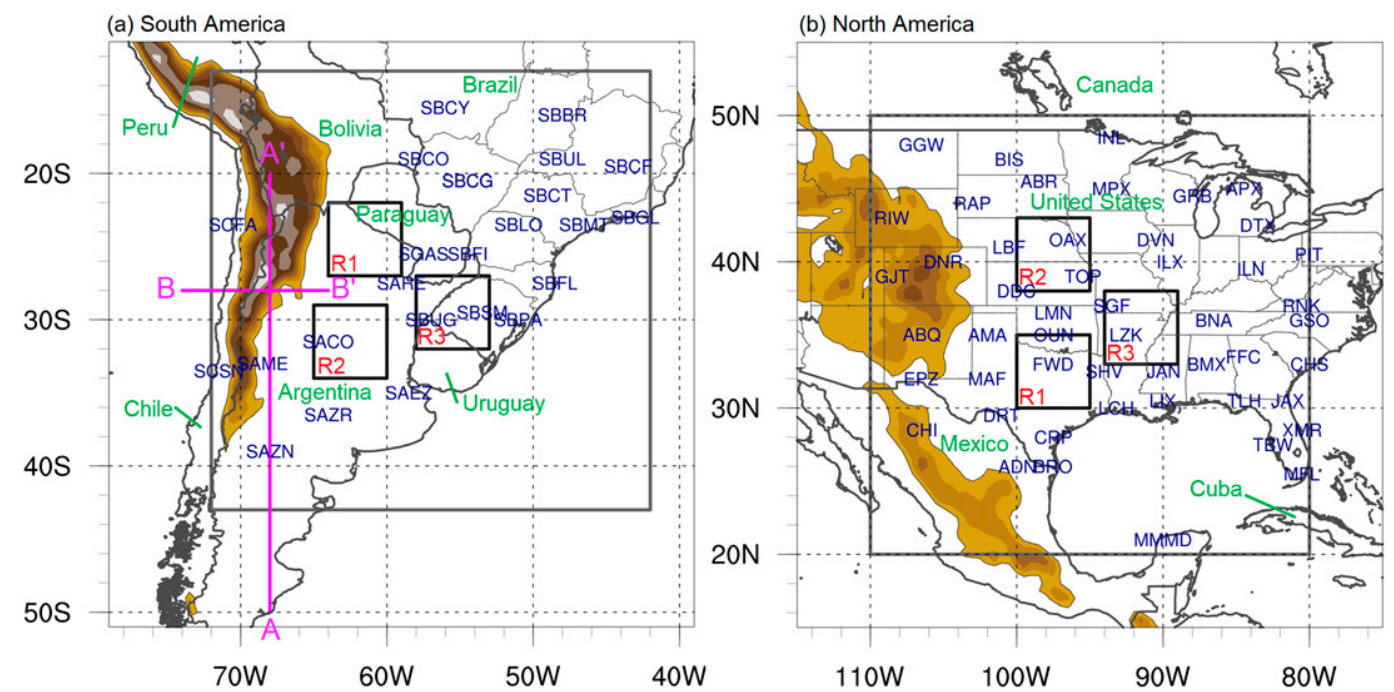

FIG. 1. Study areas (gray squares) in (a) SA and (b) NA. Orography is shaded every $500 \mathrm{~m}$ starting at $1500 \mathrm{~m}$. The black squares show the three $5^{\circ} \times 5^{\circ}$ regions in each continent used in the composites (details in the text). The names of the sounding sites located within the study areas are shown in blue. The $\mathrm{AA}^{\prime}$ and $\mathrm{BB}^{\prime}$ lines depict the location of the cross sections in Fig. 10. The borders of the states of the United States and Brazil are shown in thinner gray contours.

\section{Data and methodology}

This study was focused on midlatitudes and subtropical latitudes of NA and SA, east of the Rockies and Andes, respectively. The NA study area is bounded by $20^{\circ}-50^{\circ} \mathrm{N}$ and $110^{\circ}-80^{\circ} \mathrm{W}$; the SA study area is bounded by $13^{\circ}-43^{\circ} \mathrm{S}$ and $72^{\circ}-42^{\circ} \mathrm{W}$ (Fig. 1 ).

\section{a. Dataset}

The main analyses in this paper were constructed using the NCEP Climate Forecast System Reanalysis (CFSR; Saha et al. 2010), which has a native horizontal resolution of T382 $(\sim 38 \mathrm{~km}$, interpolated to a horizontal grid spacing of $\left.0.5^{\circ} \times 0.5^{\circ}\right)$ and is available at synoptic hours $(0000,0600,1200$, and 1800 UTC). Because the CFSR is a global reanalysis, it allows a direct comparison between NA and SA by applying the same analysis methods in both continents. Observed soundings from the University of Wyoming website (http://weather. uwyo.edu/upperair/sounding.html) were also used to validate the methodology.

The observed soundings network in SA has only a few observations near the Andes in Paraguay, northern Argentina, and Bolivia (Fig. 1). The lack of soundings in this area results in a deficient representation of meteorological phenomena east of the Andes. As a result, the intensity of the low-level jet in numerical models is underestimated (Salio et al. 2007). The majority of SA soundings are available only after 2000 , and several periods in the time series had either no soundings or soundings only at one synoptic time (e.g., 0000 UTC). We chose the CFSR for this research because of the low number of soundings in SA east of the Andes and the lack of continuity in their time series.

Four examples of typical EMLs in observed and CFSR soundings are shown in Fig. 2: two in SA (Figs. 2a,b) and two in NA (Figs. 2c,d). Small differences are observed in the wind and temperature profiles, but the dewpoint temperature profiles present large discrepancies in some layers. Other research found the same difficulty of reanalysis datasets to correctly represent the moisture profiles (e.g., Bao and Zhang 2013; Chen et al. 2014). The more pronounced differences in the temperature profile are found near the EML base and are associated with the coarser vertical resolution of the CFSR. The nearly dry-adiabatic $\gamma$ within the EML is well represented by the CFSR.

We performed a comparison of 6214 observed soundings with CFSR soundings. Both observed and CFSR soundings had to exhibit EMLs. The EMLs were identified using the methodology presented in the next subsection. Table 1 presents the differences in EML characteristics between observed and CFSR soundings. There is no statistically significant (95\% confidence using the Student's $t$ test) difference between EML bases in observed and CFSR soundings. The EML thickness, however, is greater in CFSR soundings by nearly $15 \mathrm{hPa}$. The EML $\gamma$ is lower (average difference of $0.68 \mathrm{~K} \mathrm{~km}^{-1}$ ), and the EML $\theta$ is higher (average difference of $0.55 \mathrm{~K}$ ) in CFSR soundings. The differences between SA observed and CFSR soundings are also greater than NA soundings 

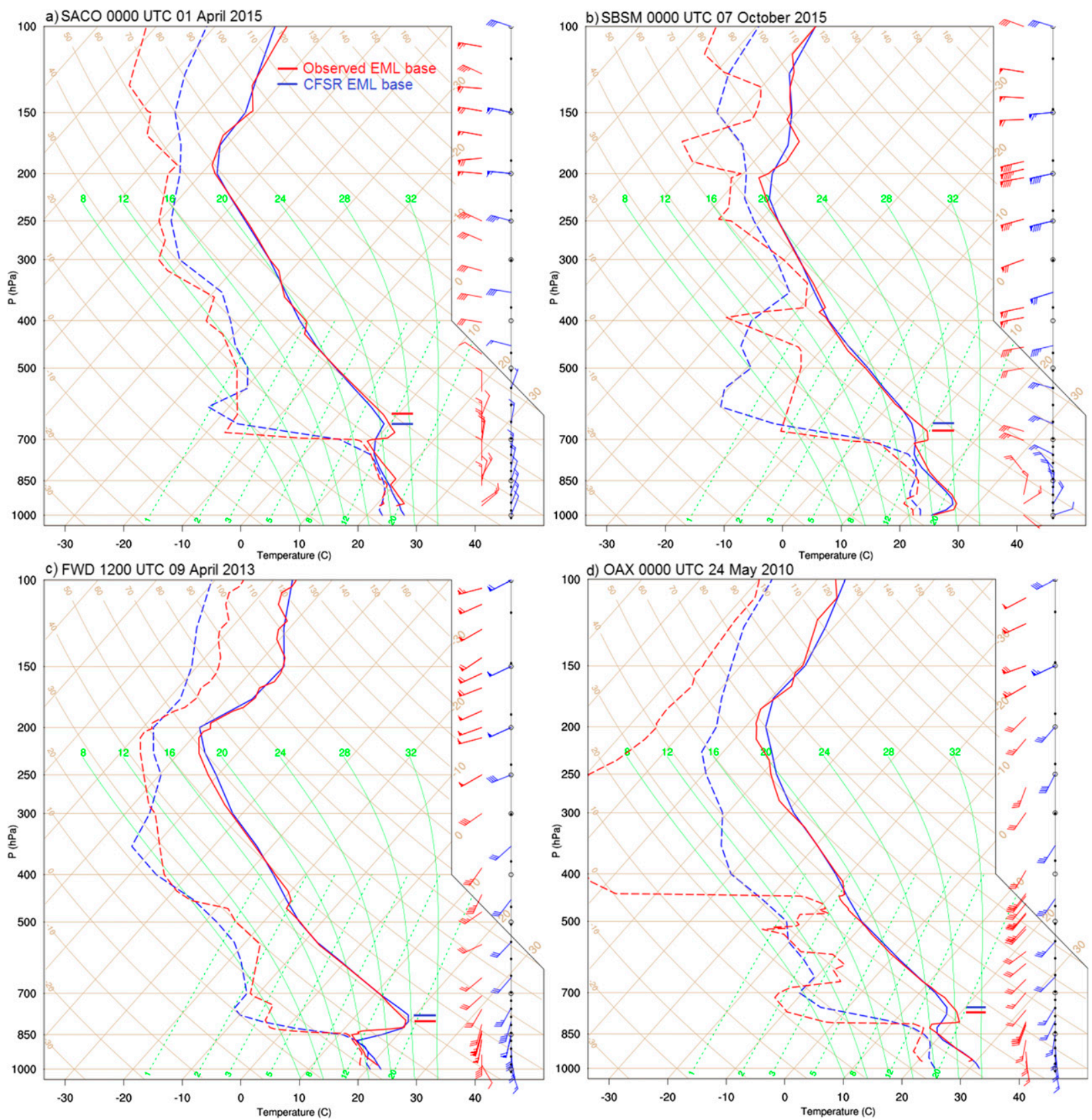

FIG. 2. Observed (red) and CFSR (blue) EML soundings at (a) Cordoba, Argentina (SACO), at 0000 UTC1 Apr 2015, (b) Santa Maria, Brazil (SBSM), at 0000 UTC 7 Oct 2015, (c) Fort Worth, TX (FWD), at 1200 UTC 9 Apr 2015, and (d) Omaha, NE (OAX), at 0000 UTC 24 May 2010. Figure 1 shows the locations of the sounding sites. The colored dashes indicate the EML bases in each sounding. CFSR soundings were taken in the closest grid point relative to the station coordinates.

for most of the parameters, which is likely due to the lower number of observations in SA that leads to relatively lower quality of the reanalysis. The differences between observed and CFSR soundings are related to numerous factors, such as data assimilation and coarser vertical resolution of the reanalysis. However, the errors are sufficiently small to allow climatological studies using reanalysis (Brooks et al. 2003), and the reanalysis provides a better areal/temporal coverage than observed soundings.

\section{b. Definition of elevated mixed layer}

We define an EML as a layer having a $\gamma$ of at least $7.5 \mathrm{~K} \mathrm{~km}^{-1}$ and thickness of at least $150 \mathrm{hPa}$, with its 
TABLE 1. Averages and standard deviations (std. dev.) of the differences between observed EML soundings and CFSR EML soundings. A positive average results from higher value of the parameter in observed soundings. Boldface values indicate statistically significant differences between observed and CFSR soundings. Four stations in SA and four in NA are shown as examples.

\begin{tabular}{|c|c|c|c|c|c|c|c|c|c|}
\hline \multirow[b]{2}{*}{ Station } & \multirow[b]{2}{*}{ Soundings } & \multicolumn{2}{|c|}{ EML base $(\mathrm{hPa})$} & \multicolumn{2}{|c|}{ EML thickness $(\mathrm{hPa})$} & \multicolumn{2}{|c|}{$\operatorname{EML} \gamma\left(\mathrm{K} \mathrm{km}^{-1}\right)$} & \multicolumn{2}{|c|}{ EML $\theta(\mathrm{K})$} \\
\hline & & Avg & Std dev & Avg & Std dev & Avg & Std dev & Avg & Std dev \\
\hline SACO & 33 & 3.15 & 46.77 & -39.67 & 73.23 & 0.60 & 0.32 & -0.23 & 3.03 \\
\hline SARE & 42 & 8.99 & 41.33 & -22.81 & 70.23 & 0.75 & 0.45 & -1.52 & 2.35 \\
\hline SBFI & 140 & 15.69 & 47.17 & -2.51 & 53.23 & 0.45 & 1.04 & -1.10 & 2.57 \\
\hline SBUG & 96 & 17.44 & 48.00 & -18.19 & 84.60 & 0.47 & 0.74 & -0.98 & 2.52 \\
\hline OUN & 346 & 0.27 & 43.16 & -11.87 & 61.51 & 0.74 & 0.46 & -0.57 & 2.12 \\
\hline FWD & 488 & 4.95 & 41.37 & -7.17 & 64.47 & 0.66 & 0.46 & -0.50 & 1.99 \\
\hline TOP & 377 & -3.76 & 44.94 & -16.51 & 66.01 & 0.67 & 0.49 & -0.79 & 2.54 \\
\hline OAX & 273 & -3.43 & 45.41 & -12.00 & 56.67 & 0.67 & 0.42 & -0.39 & 1.83 \\
\hline Total & 6214 & 1.03 & 45.63 & -15.26 & 64.79 & 0.68 & 0.49 & -0.55 & 2.21 \\
\hline
\end{tabular}

base higher than $1000 \mathrm{~m}$ above ground level. The base is considered the first pressure level, from bottom to top, to have $\gamma$ greater than or equal to $7.5 \mathrm{~K} \mathrm{~km}^{-1}$. This $\gamma$ threshold is lower than that used in other research [BE10 and Cordeira et al. (2017) used $8.0 \mathrm{~K} \mathrm{~km}^{-1}$ ] because the CFSR has less steep $\gamma$ in the EML than observed soundings (Table 1). An analysis of different thresholds was conducted, and a $\gamma$ of $7.5 \mathrm{~K} \mathrm{~km}^{-1}$ in the CFSR soundings was in good agreement with EMLs in observed soundings (Fig. 2). A threshold of $150 \mathrm{hPa}$ for EML thickness was used by Cordeira et al. (2017) and is less restrictive than the other thresholds tested (between 150 and $250 \mathrm{hPa}$ ). The mean EML thicknesses, shown in section $3 \mathrm{a}$, are generally greater than $200 \mathrm{hPa}$, so $150 \mathrm{hPa}$ is a suitable EML thickness threshold. Also, the relative humidity at the top of the EML must be higher than at the base, as in BE10.

The term EML is used to refer to a layer that has been mixed through surface radiative warming over higher terrain and advected over lower terrain (e.g., LW91; BE10). Even though elevated layers with steep $\gamma$ in SA may be formed by other physical processes, in this paper, we use the term EML to refer to these layers as well. Several authors (e.g., LW91; Cordeira et al. 2017) also refer to layers with steep $\gamma$ as EMLs without discriminating the physical processes responsible for their formation. Mechanisms other than horizontal advection can play an important role in increasing the $\gamma$ in NA as well (BE10).

Because one of the main foci of this research is the association of EMLs with severe thunderstorm environments, we require that EML grid points must have at least $100 \mathrm{~J} \mathrm{~kg}^{-1}$ of most unstable CAPE (MUCAPE). This threshold prevents EMLs generated by dynamically forced subsidence behind upper-level troughs from being identified (J. M. Cordeira 2015, personal communication). We also tested this threshold by comparing the CFSR EML soundings with the observed EML soundings after upper-level trough passage. The sensitivity tests showed that EMLs behind upper-level troughs are generally associated with zero MUCAPE because the low-level air is relatively cold. The composites shown in section 3 corroborate the efficiency of this methodology in eliminating these cases.

Our automated algorithm proceeds as follows: 1) verify if a grid point has MUCAPE of at least $100 \mathrm{~J} \mathrm{~kg}^{-1}$; 2) if so, look for a pressure level, from bottom to top, with $\gamma$ of at least $7.5 \mathrm{~K} \mathrm{~km}^{-1}$;3) verify if this $\gamma$ threshold is continuously observed in other levels above, reaching at least $150 \mathrm{hPa}$ in thickness; and 4) verify if $\mathrm{RH}$ in the first level (EML base) is lower than in the last level (EML top) with the lapse-rate threshold.

If these sequential criteria are met, an EML is attributed to that grid point at that synoptic time. The algorithm also verifies if the $\gamma$ below the EML base is higher than $7.5 \mathrm{~K} \mathrm{~km}^{-1}$. If so, the EML is not accounted, because it is, in fact, a surface-based mixed layer. Because $\gamma$ tends to $\Gamma_{d}$ in the upper troposphere, upperlevel dry-adiabatic layers are discarded by limiting the EML bases to the $500-\mathrm{hPa}$ level. This test is done for every grid point in the study areas (Fig. 1) in the 32 years of the CFSR. For every identified EML, the base level, thickness, mean $\gamma$, and mean $\theta$ are taken into account.

\section{c. Synoptic-scale composite analyses}

CFSR-based composite analyses were generated over three $5^{\circ} \times 5^{\circ}$ regions for synoptic times with EMLs in both continents. Two regions were located close to the mountains at different latitudes [region 1 (R1) in lower latitudes and region $2(\mathrm{R} 2)$ in higher latitudes]. A third region (R3) was chosen between $\mathrm{R} 1$ and $\mathrm{R} 2$ but was located farther east (Fig. 1). All three regions are located within the 4\% EML frequency contour (Fig. 3). Composite analyses in R1 and R2 illustrate synoptic flow configurations associated with EMLs in the frequency maximum region (R1) and poleward-shifted 

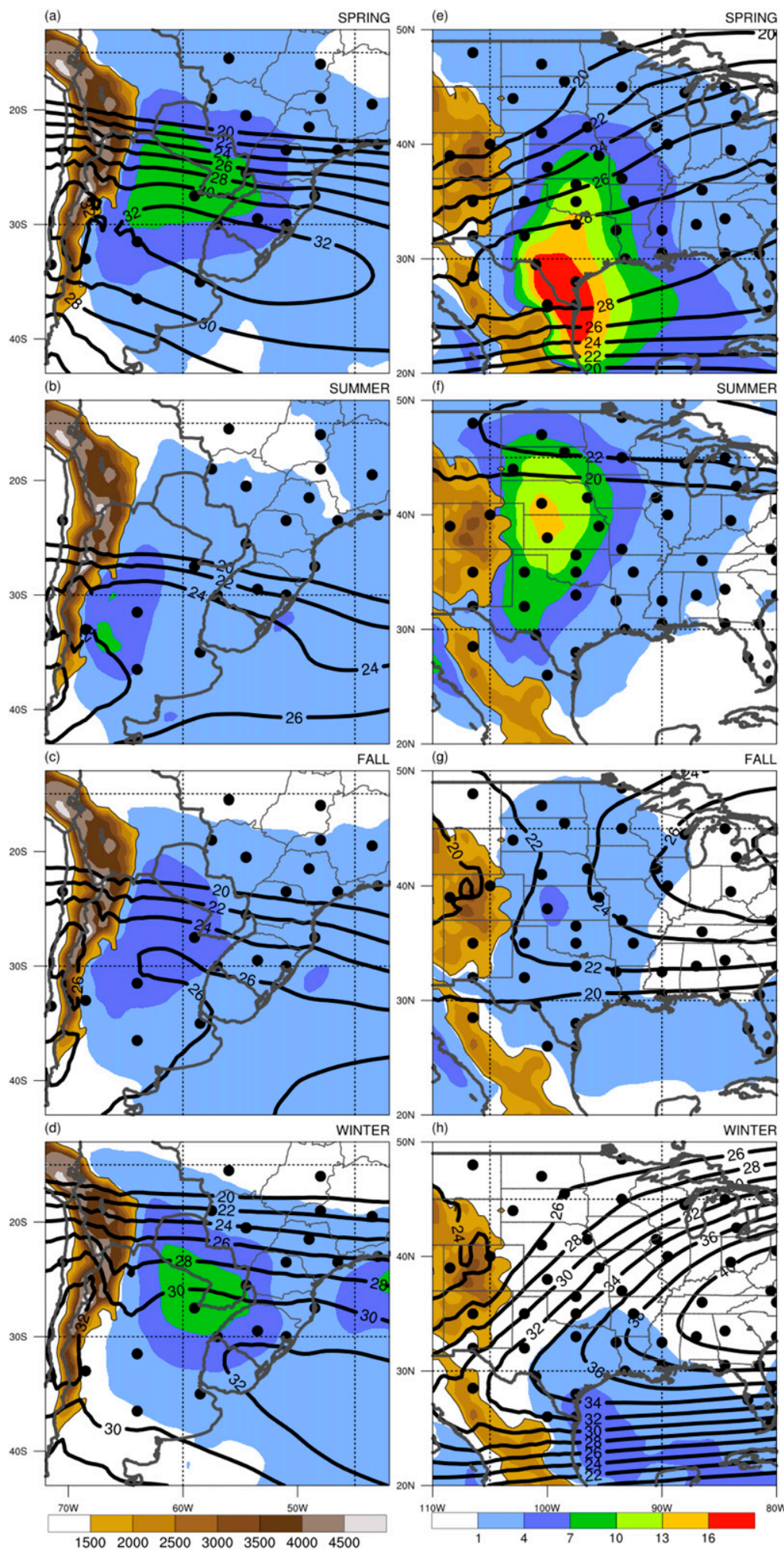

FIG. 3. Percentage of synoptic times with EML (shaded) and mean seasonal 250-hPa wind speed $\left(\mathrm{m} \mathrm{s}^{-1}\right.$, black contours every $2 \mathrm{~m} \mathrm{~s}^{-1}$ starting at $\left.20 \mathrm{~m} \mathrm{~s}^{-1}\right)$ for (a) spring, (b) summer, (c) fall, and (d) winter in SA, and (e) spring, (f) summer, (g) fall, and (h) winter in NA. Orography is shaded every $500 \mathrm{~m}$ starting at $1500 \mathrm{~m}$. Black points are the sounding sites. 
EMLs (R2), respectively. Composite analyses in R3 location illustrate the synoptic flow configurations of EMLs that have transported downstream from their origin. Hereafter, we will use the term "region" to refer to the $5^{\circ} \times 5^{\circ}$ area where the EML is located in the composites.

If an EML was identified in at least $80 \%$ of the grid points within these $5^{\circ} \times 5^{\circ}$ areas ( 97 of 121 grid points), this synoptic time was considered to have an EML over the region. Several other percentages between $70 \%$ and $100 \%$ were tested by comparing observations with the identification method, and $80 \%$ was the percentage used in this research. Values higher than $80 \%$ are too restrictive, that is, the number of EML cases decreases significantly by using higher percentages, which is attributed to the typical heterogeneity in areal coverage of the EMLs. A percentage of $100 \%$ was rarely observed. Values lower than $80 \%$ were associated with a higher number of cases, but with no change in the general synoptic pattern.

The diurnal cycle is not considered in the composites. Even though EML formation in NA relates to the diurnal cycle (Carlson and Ludlam 1968; LW91), the same may not be true in SA. Therefore, the composited cases mix EMLs occurring at any time of the day to allow a comparison between the continents. The composite fields were also used to estimate the $\gamma$ tendency equation terms [(1); BE10]. All the variables in the equation are directly available in CFSR. Only R1 composites were used for the $\gamma$ tendency equation computation because R1 has the highest frequency of EMLs.

Several parameters commonly used in severe thunderstorm forecasting and research were composited. The parameters are surface-based CAPE (SBCAPE), MUCAPE, CIN of the most unstable parcel (hereafter CIN), lifting condensation level (LCL) height, stormrelative helicity $(\mathrm{SRH})$, and vertical wind difference (hereafter "wind shear"). These severe weather parameters were averaged in the $5^{\circ} \times 5^{\circ}$ areas at synoptic times with EMLs over the regions to compare their variability between the regions and continents. The LCL height was calculated with the Espy formula (Lawrence 2005). The storm motion vector for SRH calculation was estimated using the technique presented by Davies and Johns (1993). The Student's $t$ test was used to verify if the differences in severe weather parameters between different regions are statistically significant.

Three-month seasons were used to define EML characteristics and to construct the composite analyses. Here, spring, for example, refers to March-May in NA and to September-November in SA, and so on. Although EML composite analyses were constructed for all four seasons, in this paper we will only focus spring cases, when the Americas are most frequently affected by severe weather (e.g., LW91; Brooks et al. 2003; Thompson et al. 2003) and when more EML cases were observed.

\section{Results and discussion}

\section{a. Climatology and EML characteristics}

Figure 3 shows the percentage of CFSR times that an EML was present in each grid point for the four seasons. EMLs are more common east of the mountain ranges in both continents. EML frequencies in SA (Figs. 3a-d) have a nearly constant maximum that varies in location throughout the year. The highest EML frequencies move from northeastern Argentina in winter (Fig. 3d) to west-central Argentina in summer (Fig. 3b), when the areal coverage is the lowest. Higher frequencies extend farther east from fall to spring (Figs. 3a-d), when uppertropospheric winds are stronger, but are restricted to the Andes foothills in summer (Fig. 3b). Figures 3a-d also indicate that there are only a few sounding sites in north/ northwestern Argentina, where most EMLs occur.

Seasonal EML variability in NA is higher, with the highest frequency observed in spring (Fig. 3e) over the south-central United States and northeastern Mexico, extending north toward the central United States. This maximum shifts poleward to the north-central United States in summer with a reduced magnitude (Fig. 3f). During fall and winter (Figs. 3g,h), fewer EMLs are observed in NA, and most of them occur near the Gulf of Mexico. The NA EML frequencies during spring are very similar to the findings of LW91 (their Fig. 5). The highest frequencies in the south-central United States are related to heating over high terrain in northern Mexico. From late spring to summer, heating is also strong over the high terrain in the western United States, which favors higher frequencies farther north in the central and north-central United States. (Fig. 3f). Lower solar elevation angles, snow cover over the Rockies, and lower CAPE over NA during fall and winter are consistent with lower EML frequencies during these seasons (Figs. 3g,h).

The EML bases over SA are generally located between 600 and $650 \mathrm{hPa}$ (Figs. 4a-d). These bases are higher $(550-600 \mathrm{hPa})$ during fall (Fig. 4c) and lower $(700-650 \mathrm{hPa})$ in some parts of the study area during summer and spring (Figs. 4a,b). EML thicknesses decrease eastward in all seasons. The greatest EML thicknesses occur in western Argentina during winter (Fig. 4d), while shallower EMLs occur in summer (Fig. 4b). The occurrence of thicker EMLs during spring and winter (Figs. 4a,d) is associated with a stronger 250-hPa jet in these seasons (Figs. 3a,d). 

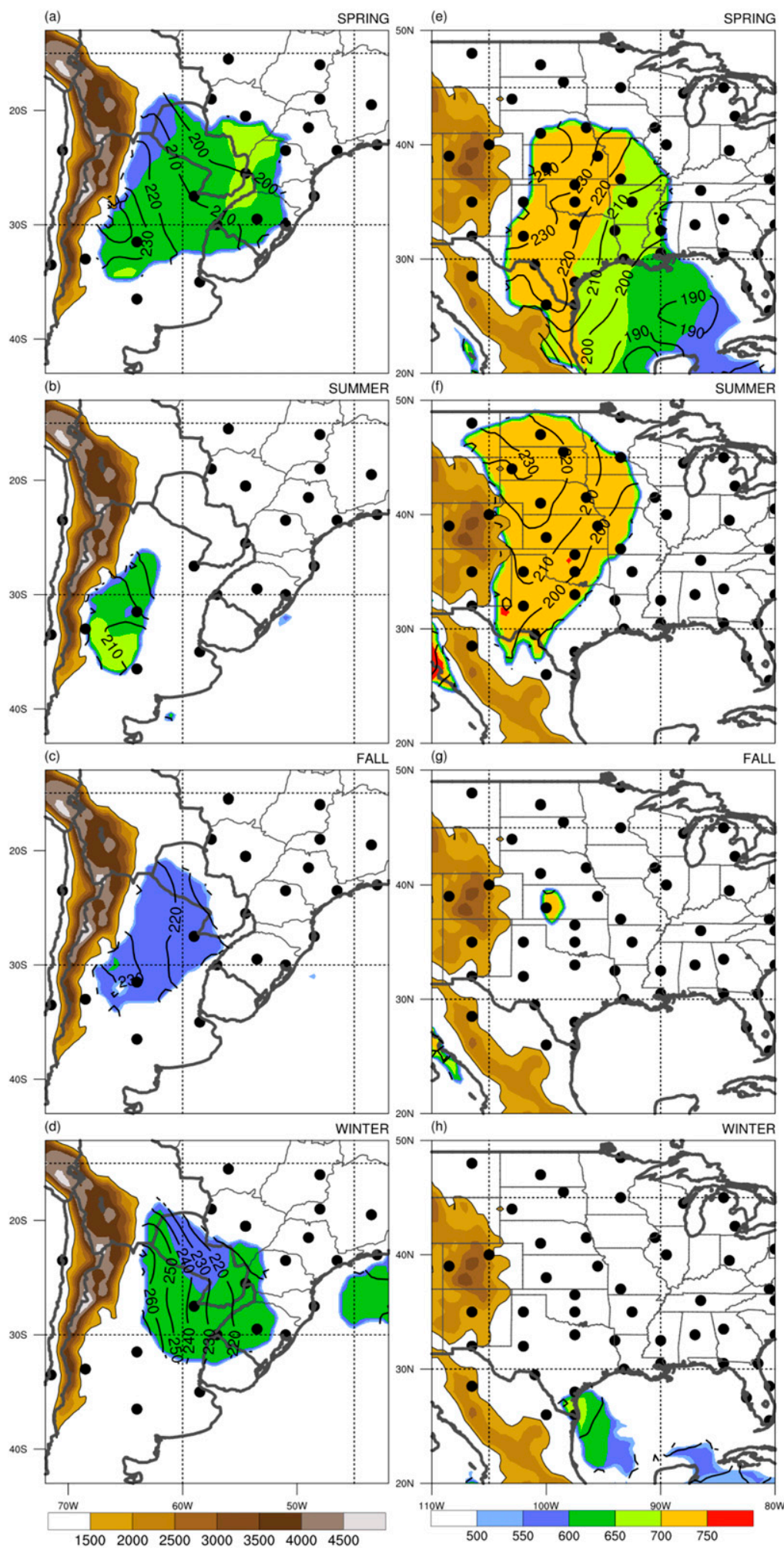

FIG. 4. Mean EML base level (hPa, shaded) and mean EML thickness (hPa, black contours every $10 \mathrm{hPa}$ ) for (a) spring, (b) summer, (c) fall, and (d) winter in SA, and (e) spring, (f) summer, (g) fall, and (h) winter in NA. All variables are plotted only in grid points with percentages (as in Fig. 2) greater than $4 \%$. Orography is shaded every $500 \mathrm{~m}$ starting at $1500 \mathrm{~m}$. Black points are the sounding sites. 
The main difference of EMLs in NA compared to SA is their base heights (Fig. 4). The heights vary from 700 to $750 \mathrm{hPa}$ in the areas east of the Rockies during spring and summer (Figs. 4e,f) and are approximately $100 \mathrm{hPa}$ lower than in SA east of the Andes. SA EML thicknesses are maximized in winter in western Argentina (Fig. 4d), when the winds aloft are the strongest, whereas over NA, the EMLs have little variation in the thickness maximum (Figs. 4e,f). NA EML thicknesses present a northward shift from spring to summer, with decreasing thicknesses over the south-central United States and increasing thicknesses over the north-central United States (Figs. 4e,f). This northward shift is a result of deeper PBL mixing over higher terrain occurring farther north in summer (LW91).

The highest mean EML $\gamma$ are found close to the mountain ranges in both continents (Fig. 5). The highest $\gamma$ in SA occur in winter (Fig. $5 \mathrm{~d}$ ), exceeding $8.0 \mathrm{~K} \mathrm{~km}^{-1}$ in northern Argentina. EMLs in SA also present the lowest $\gamma$ in summer (Fig. 5b). In NA, the highest $\gamma$ occur in spring in the central United States (more than $8.1 \mathrm{~K} \mathrm{~km}^{-1}$; Fig. 5e), and farther north in summer (Fig. 5f), following the northward shift in EML frequencies (Figs. 3e,f). During spring and summer, when severe thunderstorms are more common, the $\gamma$ associated with EMLs over NA is higher than over SA in general (Figs. 5a,b,e,f).

The mean $\theta$ in the EML (hereafter EML $\theta$ ) is higher in SA in all seasons (Fig. 5) as compared to NA. This result is expected because EML bases in SA are higher and $\theta$ usually increases with height in the troposphere. In spring, SA EML $\theta$ distribution (Fig. 5a) is characterized by higher values over northern Paraguay and southern Bolivia and decreasing southward to central Argentina, where the isentropes are nearly zonal. The meridional gradient of EML $\theta$ in west-central Argentina persists in the other seasons (Figs. 5b-d). Unlike SA, NA EML $\theta$ values are quasi constant in spring and summer (Figs. 5e,f), likely a result of the homogeneous horizontal advection of surface-based mixed layers (BE10). The EML $\theta$ values between 316 and $320 \mathrm{~K}$ in NA are in good agreement with the findings of LW91 (their Fig. 10).

\section{b. Composites and $\gamma$ tendency equation}

\section{1) SyNOPTIC-SCALE ENVIRONMENT}

Standardized 250-hPa geopotential height anomalies (Fig. 6) exhibit a similar large-scale pattern in all composites, with an anomalous trough over the mountain ranges and an anomalous ridge downstream. In SA, the ridge and trough anomalies' positions are similar in R1 and R3 composites (Figs. 6a,c), but the ridge is stronger and closer to the EML location in R2 composites (Fig. 6b). The 250-hPa wind magnitude has two maxima: one located over the Andes around $30^{\circ} \mathrm{S}$, and the other extending from eastern Argentina to the Atlantic Ocean at nearly $40^{\circ} \mathrm{S}$. The EML region is located in the equatorward entrance region of the jet in R1 and R2 composites (Figs. 6a,b), and farther east in R3 composites (Fig. 6c).

A similar $250-\mathrm{hPa}$ pattern is observed in NA composites (Figs. 6d-f). An anomalous trough is located over the Rockies and an anomalous ridge over the central United States. The position of the anomalous ridge in relation to the anomalous trough varies between the NA composites, occurring at lower latitudes in R1 and R3 (Figs. 6d,f) and at the same latitude in R2 (Fig. 6e). The jet stream is poleward in R2 composites in comparison to R1 and R3 composites, similarly to SA, which is caused by the greater amplitude of the flow. The upper-level flow amplitude is greater in NA, whereas in $\mathrm{SA}$, the trough and ridge are positively tilted and favor stronger zonal winds.

Vertical motion composites ( $\omega$; Fig. 7) in the EML (600-400-hPa layer in SA and 700-500-hPa layer in NA) show that ascent occurs over and mainly poleward of the $\mathrm{R} 1-\mathrm{R} 3$ regions. This area of ascent is downstream of the upper-level trough and in the equatorward entrance region of the jet (Fig. 6), where ascent is favored by ageostrophic circulations (Uccellini and Johnson 1979). Subsidence occurs east of the mountain ranges, mainly in SA.

The $\gamma$ values increase rapidly from west to east of the Andes following the mean flow (Figs. 7a-c), evidence of the role of the mountains in steepening the $\gamma$. Over NA, high $\gamma$ is observed over the plateaus of northern Mexico in $\mathrm{R} 1$ and $\mathrm{R} 3$ composites (Figs. 7d,f) and in the western United States in R2 composites (Fig. 7e). High $\gamma$ values in the 700-500-hPa layer over these areas, where the surface pressure is nearly $800-700 \mathrm{hPa}$, are related to surface-based mixed layers. The similarity between $\gamma$ in NA R1 and R3 composites (Figs. 7d,f) indicates the EML is advected from northern Mexico in both cases, but the stronger mean winds are responsible for greater eastward displacement of the EML in the R3 composite (Fig. 7f). EMLs occurring over NA R2 are advected by the mean flow from the U.S. Rockies. SA R3 composites (Fig. 7c) suggest the EMLs that reach farther east have their $\gamma$ reduced, whereas over NA, the EMLs maintain the high $\gamma$ along the flow (Fig. 7f). Ascent in association with lower $\gamma$, as observed in SA R3 composites, is responsible for greater $\gamma$ reduction by vertical advection [term C of (1)], as will be shown in the next subsection.

The general pattern at $850 \mathrm{hPa}$ (Fig. 8) is for lower geopotential heights to occur near the mountain ranges 

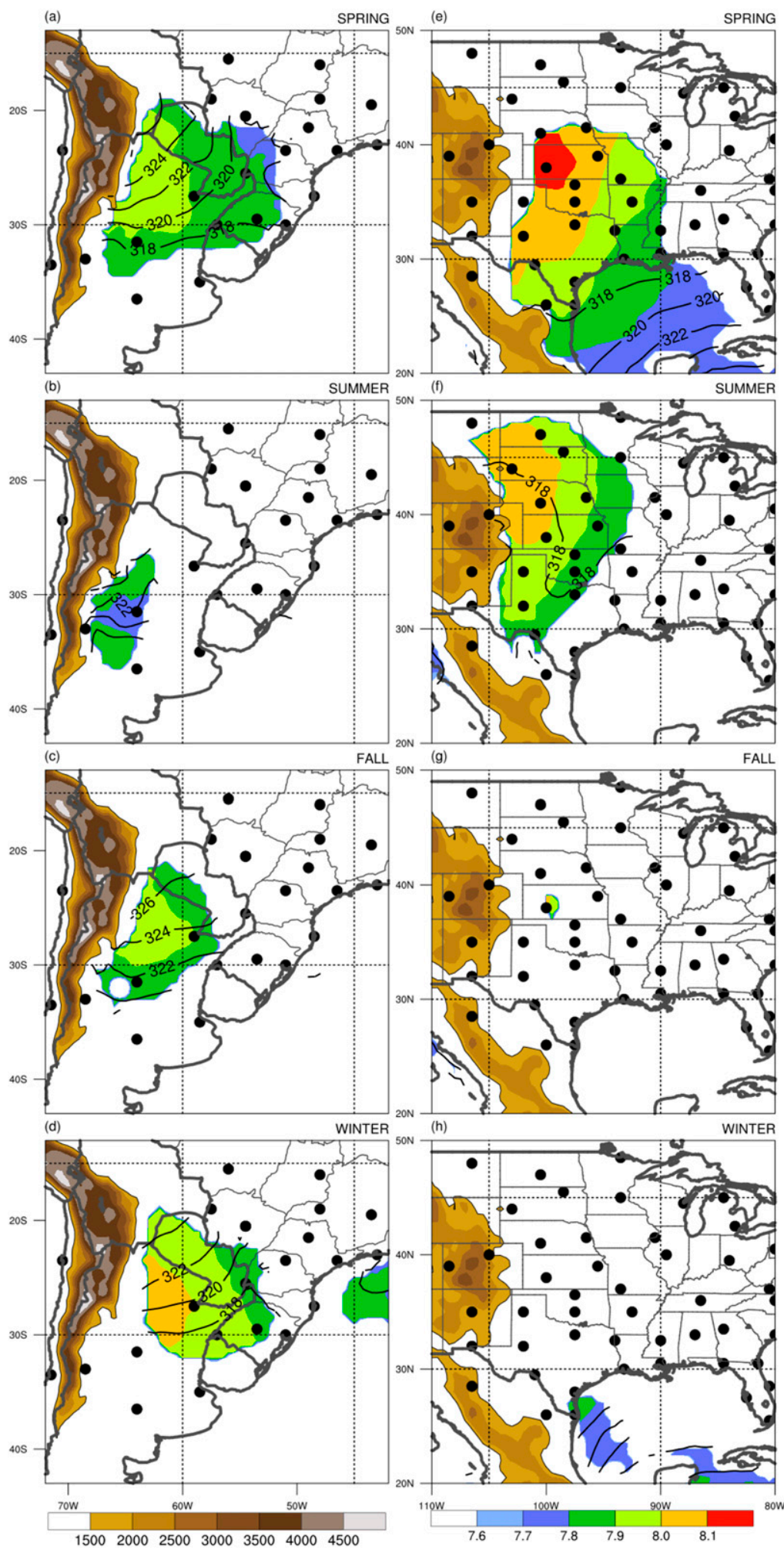

FIG. 5. Mean EML $\gamma\left(\mathrm{K} \mathrm{km}^{-1}\right.$, shaded) and $\theta$ (K, black contours every $\left.2 \mathrm{~K}\right)$ for (a) spring, (b) summer, (c) fall, and (d) winter in SA, and (e) spring, (f) summer, (g) fall, and (h) winter in NA. All variables are plotted only in grid points with percentages (as in Fig. 2) greater than 4\%. Orography is shaded every $500 \mathrm{~m}$ starting at $1500 \mathrm{~m}$. Black points are the sounding sites. 
(a) Region 1

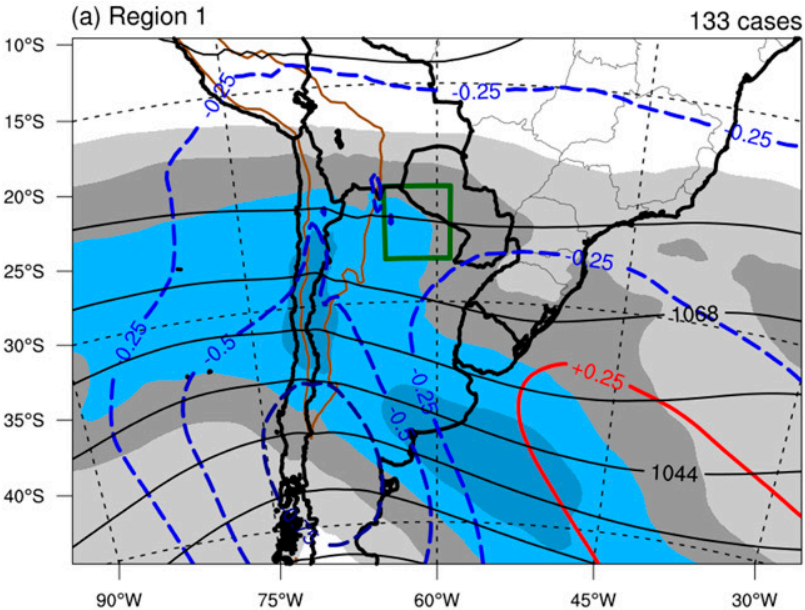

(b) Region 2 (d) Region 1

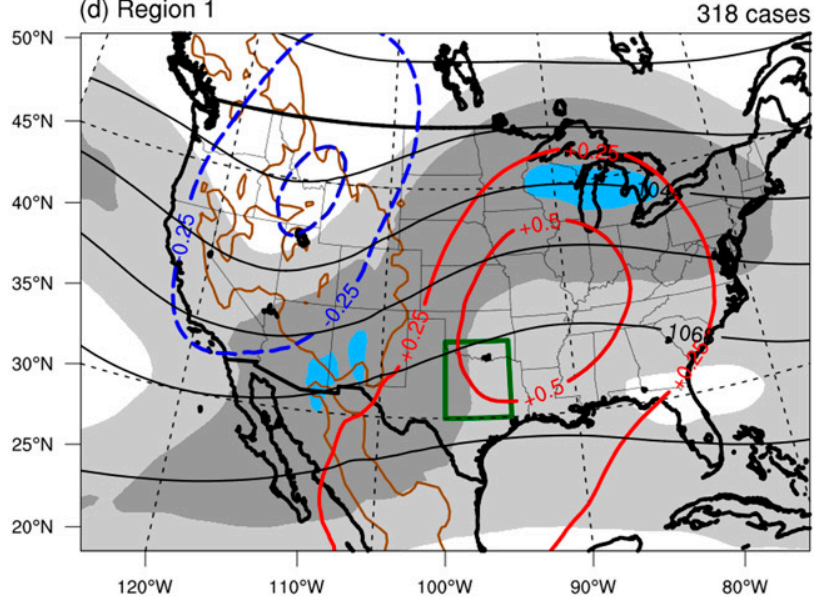

(e) Region 2
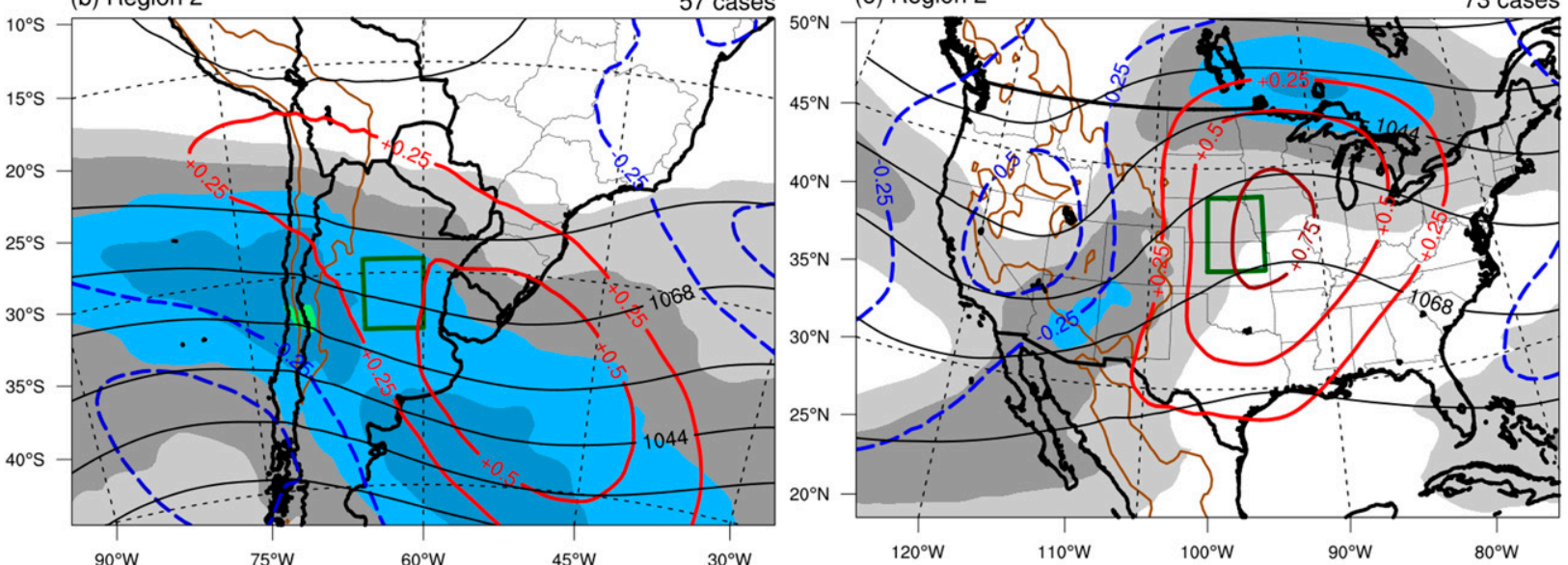

(c) Region 3

95 cases
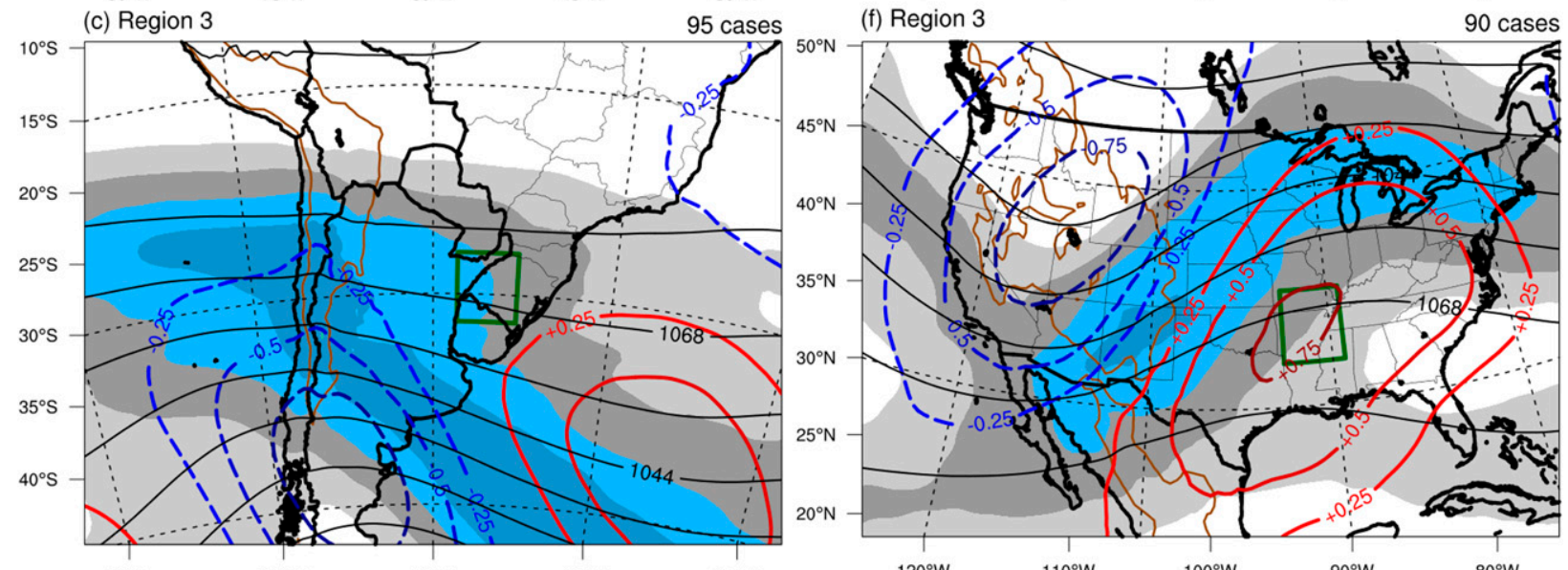

$90^{\circ} \mathrm{W}$

$75^{\circ} \mathrm{W}$

$60^{\circ} \mathrm{W}$

$45^{\circ} \mathrm{W}$

$30^{\circ} \mathrm{W}$
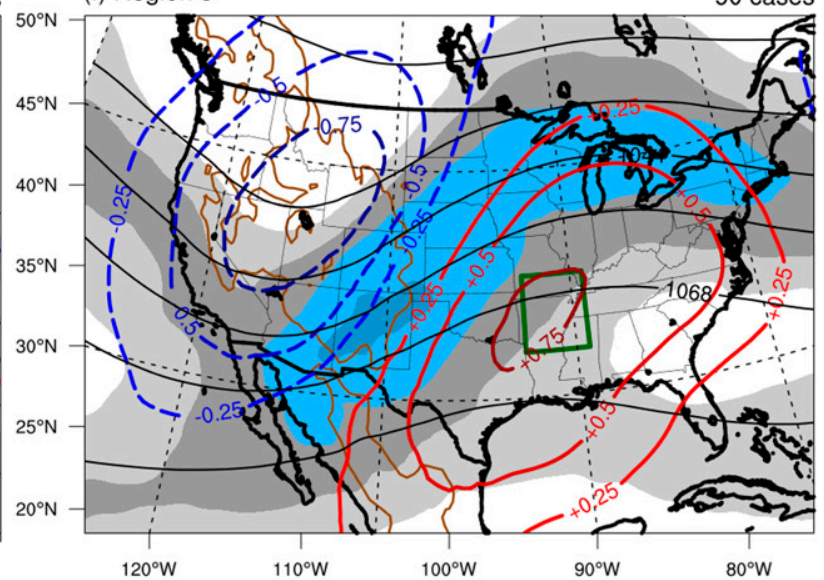

$$
20 \quad 25
$$

30

35

40

FIG. 6. Composite 250-hPa wind speed ( $\mathrm{m} \mathrm{s}^{-1}$, shaded), geopotential height (dam, black contours every 12 dam), and standardized anomalies of geopotential height (red contours for positive anomalies every 0.25 standard deviation starting at +0.25 standard deviation and blue contours for negative anomalies every -0.25 standard deviation starting at -0.25 standard deviation) for EML cases in spring in (a) R1, (b) R2, and (c) R3 of SA, and (d) R1, (e) R2, and (f) R3 of NA. The brown contour shows the 1500 -m orographic contour. The $5^{\circ} \times 5^{\circ}$ areas are drawn in green squares. 

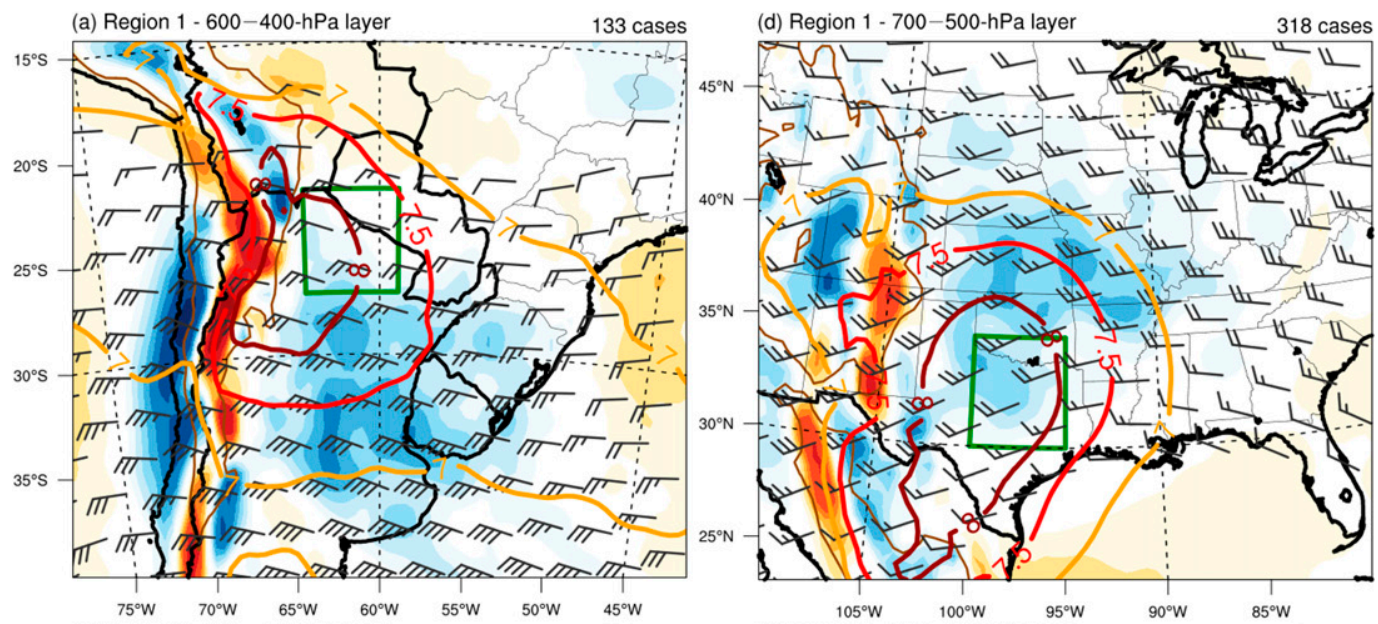

(b) Region $2-600-400-\mathrm{hPa}$ layer

57 cases
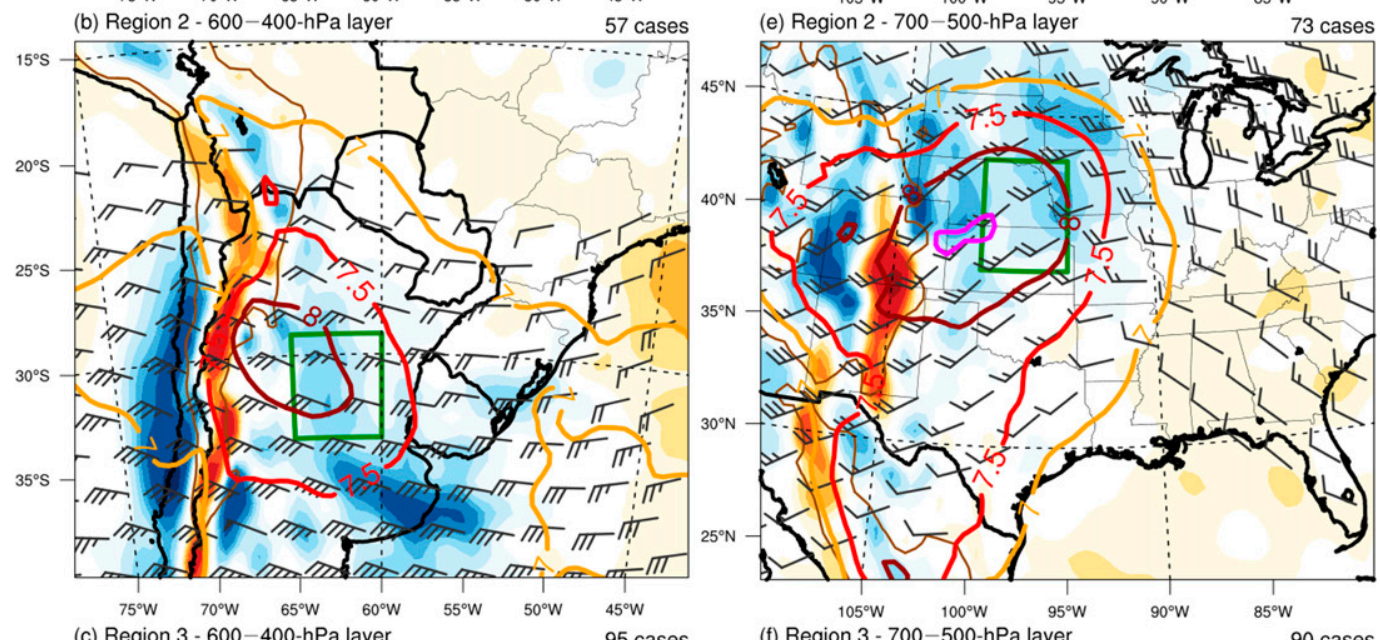

(c) Region $3-600-400-\mathrm{hPa}$ layer 95 cases
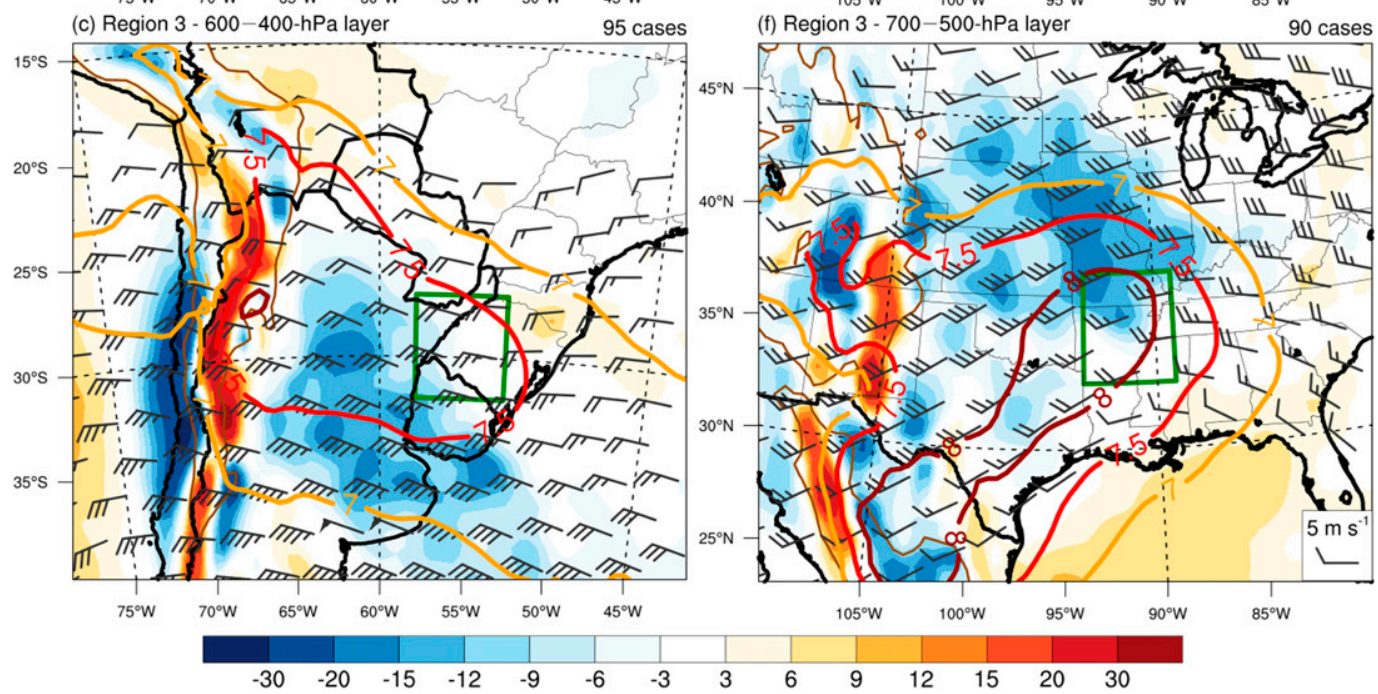

FIG. 7. Composite $\omega\left(10^{-2} \mathrm{~Pa} \mathrm{~s}^{-1}\right.$, shaded), $\gamma$ (colored contours of 7, 7.5, 8 , and $\left.8.5 \mathrm{~K} \mathrm{~km}^{-1}\right)$, and wind $\left(\mathrm{m} \mathrm{s}^{-1}\right.$, pennant is 25 , full barb is 5 , and half barb is $2.5 \mathrm{~m} \mathrm{~s}^{-1}$; only wind barbs greater than $5 \mathrm{~m} \mathrm{~s}^{-1}$ are plotted) for EML cases in spring in (a) R1, (b) R2, and (c) R3 of SA, and (d) R1, (e) R2, and (f) R3 of NA. The variables are averaged over the 600-400-hPa layer in SA and 700-500-hPa layer in NA. The brown contour shows the 1500-m orographic contour. The $5^{\circ} \times 5^{\circ}$ areas are drawn in green squares. 
(a) Region 1

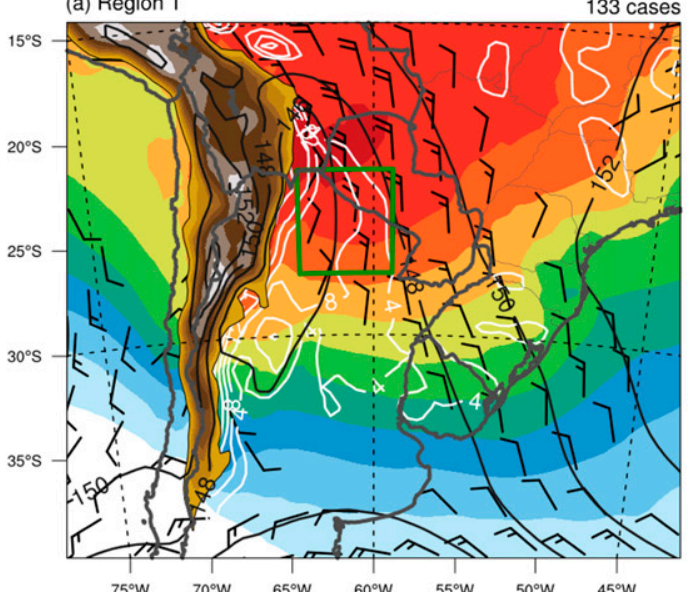

$\begin{array}{lllllllll}75^{\circ} \mathrm{W} & 70^{\circ} \mathrm{W} & 65^{\circ} \mathrm{W} & 60^{\circ} \mathrm{W} & 55^{\circ} \mathrm{W} & 50^{\circ} \mathrm{W} & 45^{\circ} \mathrm{W}\end{array}$ (b) Region 2
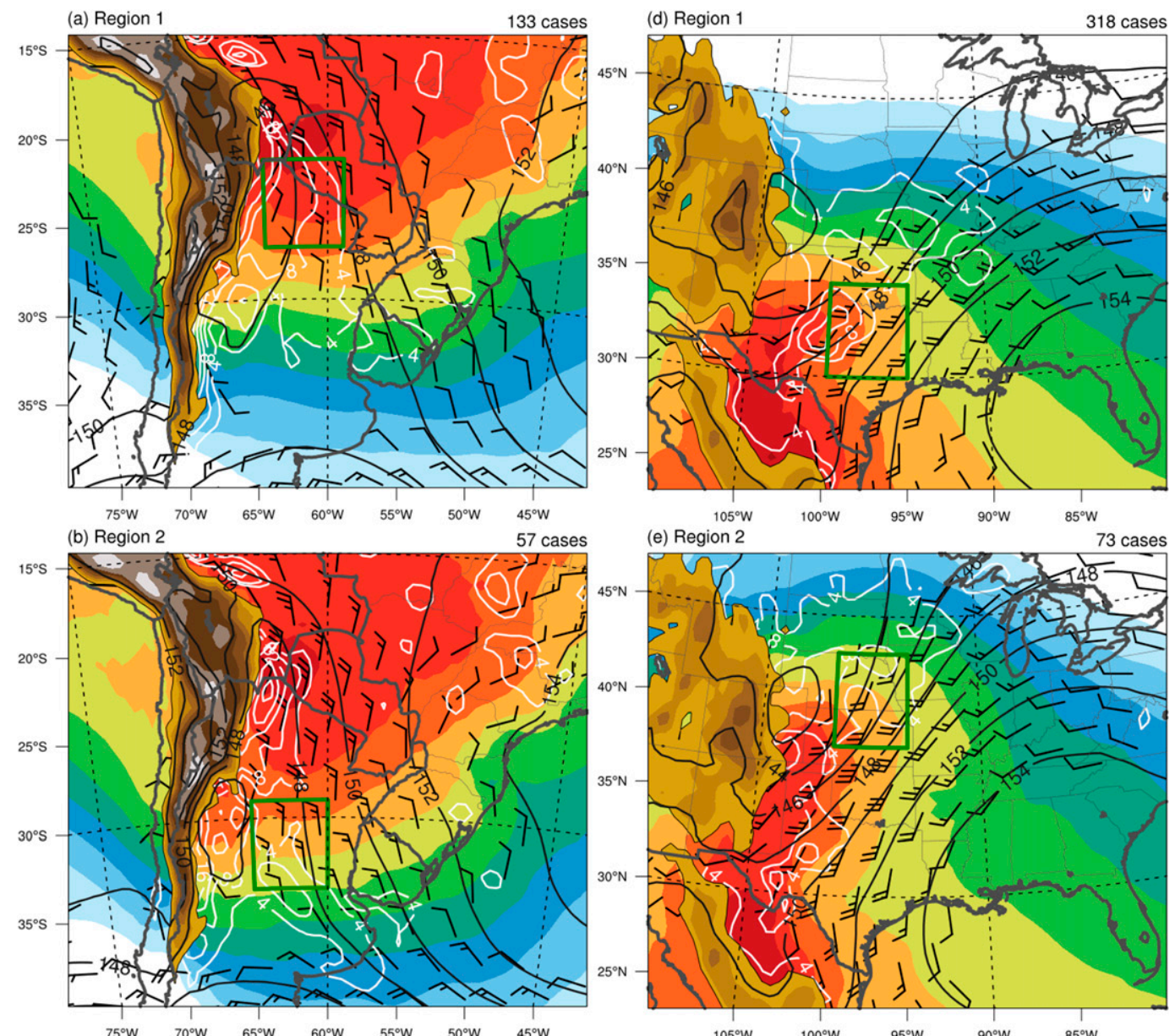

c) Region 3

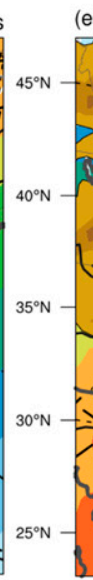

(e) Region 2 73 cases
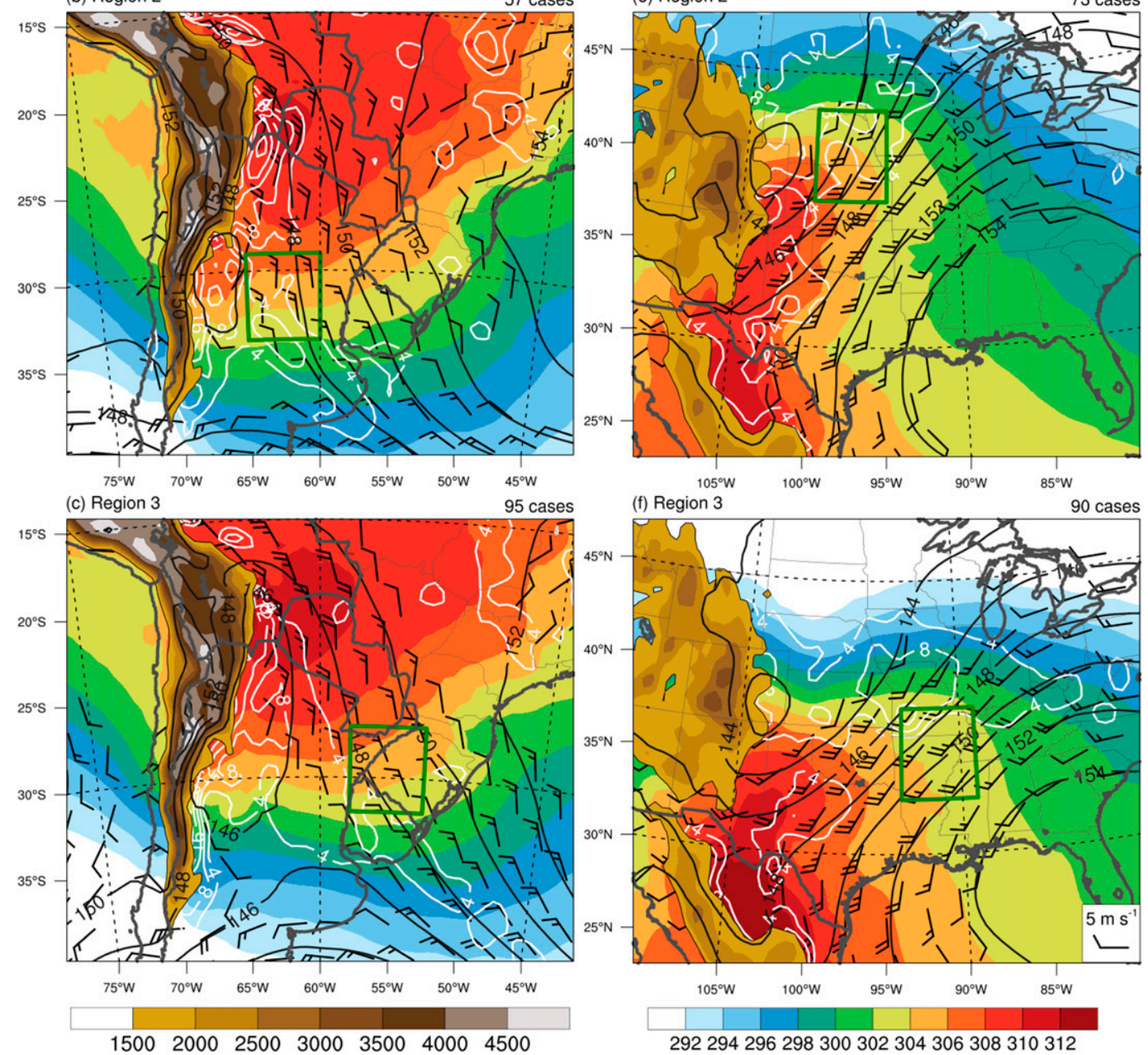

FIG. 8. Composite $850-\mathrm{hPa} \theta_{e}\left(\mathrm{~K}\right.$, shaded), wind ( $\mathrm{m} \mathrm{s}^{-1}$, pennant is 25 , full barb is 5 , and half barb is $2.5 \mathrm{~m} \mathrm{~s}^{-1}$; only wind barbs greater than $5 \mathrm{~m} \mathrm{~s}^{-1}$ are plotted), and geopotential height (dam, black contours every 2 dam) and 1000-800-hPa MFC $\left(10^{-5} \mathrm{~g} \mathrm{~kg}^{-1} \mathrm{~s}^{-1}\right.$, white contours every $\left.4 \times 10^{-5} \mathrm{~g} \mathrm{~kg}^{-1} \mathrm{~s}^{-1}\right)$ for EML cases in spring in (a) R1, (b) R2, and (c) R3 of $\mathrm{SA}$, and (d) R1, (e) R2, and (f) R3 of NA. Orography is shaded every $500 \mathrm{~m}$ starting at $1500 \mathrm{~m}$. The $5^{\circ} \times 5^{\circ}$ areas are drawn in green squares. 
with heights increasing eastward toward the subtropical anticyclones, providing a poleward-directed, confluent flow over and mainly poleward of the R1-R3 regions, where the 1000-800-hPa moisture flux convergence (MFC; Banacos and Schultz 2005) maximizes. A meridional $\theta_{e}$ gradient exists poleward of the R1-R3 regions collocated with high MFC in all composites, which relates to warm front activity (Banacos and Schultz 2005) along the trough extending east from the lee geopotential height minimum.

The highest $\theta_{e}$ values in SA are found east of the Andes around $20^{\circ} \mathrm{S}$ in all composites (Figs. 8a-c), in association with northerly flow and MFC along the mountains. The strong 850 -hPa winds collocated with MFC along the Andes between $20^{\circ}$ and $30^{\circ} \mathrm{S}$, particularly in R1 and R2 composites (Figs. 8a,b), indicate the presence of a barrier jet along the Andes foothills. The longer meridional stretch of $850-\mathrm{hPa}$ winds in the $\mathrm{R} 2$ composites (Fig. 8b) is due to the farther west location of the South Atlantic subtropical anticyclone, in comparison to the other composites, and also reflects the different location of the anomalous 250-hPa ridge in the $\mathrm{R} 2$ composites (Fig. 6b). Several climatological studies in SA relate similar low-level conditions to the occurrence of mesoscale convective systems and severe thunderstorms (e.g., Machado et al. 1998; Salio et al. 2007; Anabor et al. 2008), especially in the areas of greatest MFC.

The distribution of $850-\mathrm{hPa} \theta_{e}$ in the NA composites (Figs. 8d-f) shows maxima in northern Mexico and the southern United States. Southwesterly flow is observed from the western Gulf of Mexico toward the Great Lakes region. In the R2 composites (Fig. 8e), stronger southerly flow spreads warm/moist air northward along the Rockies, whereas in the R1 and R3 composites (Figs. 8d,f), the greater zonal component of the flow enables high $-\theta_{e}$ air to be confined to lower latitudes. All NA composites exhibit stronger 850 -hPa flow over the regions, in comparison to SA composites, and a similar pattern of higher MFC poleward of the EML location.

\section{2) ThE $\gamma$ TENDENCY EQUATION}

Figure 9 shows the quantification of the $\gamma$ tendency equation terms derived from (1) and calculated using the composite fields of 133 EML cases over SA R1 and 318 EML cases over NA R1. Term A (Figs. 9a,f) is relatively small over SA and NA, similarly to what the BE10 scale analysis had shown. The diabatic heating is responsible for $\gamma$ decrease and EML demise when convection occurs, causing the temperature profile to tend toward the moistadiabatic lapse rate (BE10). Term B (Figs. 9b,g) indicates positive tendencies in $\gamma$ over a broad area downstream of $\mathrm{R} 1$ in both continents. The positive horizontal advection of $\gamma$ is greater over NA due to the greater $\gamma$ gradient along the flow downstream of the EML plume in NA (Figs. 7a,d). Despite the lower values in comparison to NA, term B plays an important role in $\gamma$ increase due to EML transport in SA. Poleward of R1 in SA, ascent (Fig. 7a) is responsible for negative $\gamma$ tendency. Ascent is present poleward of the R1 region in NA as well (Fig. 7d), but because term C is much lower than in SA (Figs. 9c,h), this suggests the EML $\gamma$ in NA is nearly constant with height. This characteristic favors little or no $\gamma$ decrease due to term C over NA as the EML travels downstream (Fig. 7f). The reduction in $\gamma$ by ascent in SA is a factor contributing to lower $\gamma$ over SA R3 (Fig. 7c), which is farther downstream from the Andes.

Term D (Figs. 9d,i) maximizes over the mountain ranges and immediately east of the highest peaks, particularly over the Andes. Among the nonadvective terms (i.e., the terms responsible for $\gamma$ change), term $\mathrm{D}$ presents positive values over a broader area just east of the highest peaks of the Andes and is explored in more detail in this section. Term E (Figs. 9e,j) has maxima and minima along the mountains and is relatively small to the east of the mountain ranges. Term $\mathrm{E}$ depends on the difference between $\gamma$ and $\Gamma_{d}$ and is generally small within the EML (BE10).

We will next show a calculation of the twodimensional mass streamfunction $\Psi_{M}$ along selected longitudes to show the sense of the vertical circulation associated with EMLs (Fig. 10). Here, $\Psi_{M}$ is given by

$$
\Psi_{M}=\frac{2 \pi a \cos \varphi}{g} \int_{0}^{p} v d p,
$$

where $a$ is Earth's radius, $\varphi$ is the latitude, $g$ is gravity, $p$ is the pressure, and $v$ is the meridional wind component (Townsend and Johnson 1985). The $\Psi_{M}$ calculation method is described in Qin et al. (2006). We first show a pole-to-pole calculation of $\Psi_{M}$ along $85^{\circ} \mathrm{W}$ through the South Pacific subtropical anticyclone for the 133 spring cases when an EML was present east of the Andes (Fig. 10a). This calculation reveals that time-mean subsidence is present near $30^{\circ} \mathrm{S}$ on the poleward side of the time-mean thermally direct Hadley circulation beneath the subtropical jet core (Fig. 10a). This time-mean subsidence near $30^{\circ} \mathrm{S}$ is also a part of the equatorward branch of the time-mean thermally indirect circulation, whose rising branch is centered near $60^{\circ} \mathrm{S}$ (Fig. 10a). The $\Psi_{M}$ calculation from $50^{\circ}$ to $20^{\circ} \mathrm{S}$ along $68^{\circ} \mathrm{W}\left(\mathrm{AA}^{\prime}\right.$ in Fig. 1a), immediately to the east of the Andes on the same 133 days when an EML is present, shows that a thermally direct vertical circulation is present with an ascending branch equatorward of $30^{\circ} \mathrm{S}$ beneath the subtropical jet core and a descending branch poleward 

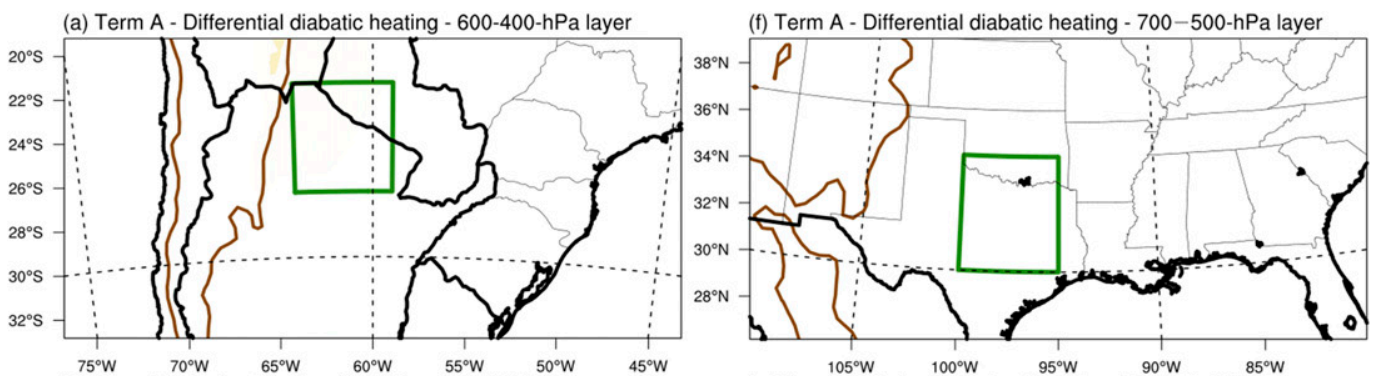

(b) Term B - Horizontal advection of $\gamma-600-400-\mathrm{hPa}$ layer

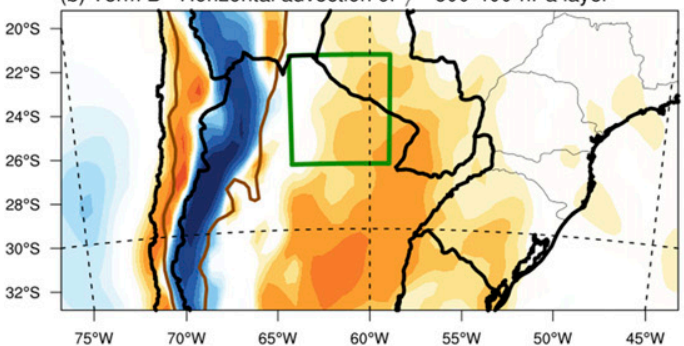

(g) Term B - Horizontal advection of $\gamma-700-500-\mathrm{hPa}$ layer

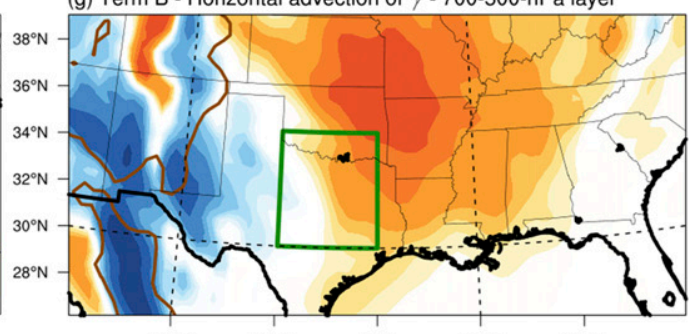

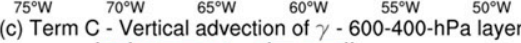

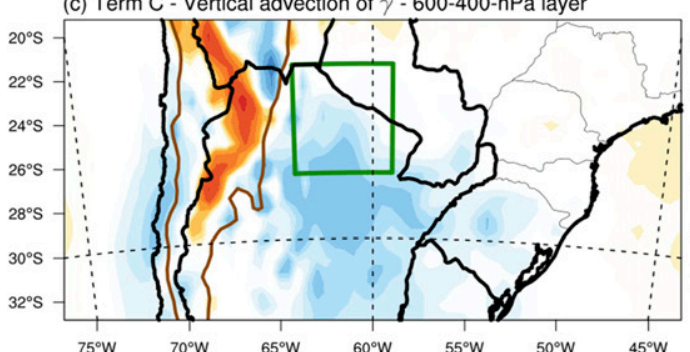

$105^{\circ} \mathrm{W}$
(h) Term $\mathrm{C}-$ Vertical advection of $\gamma-700-500-\mathrm{hPa}$ layer

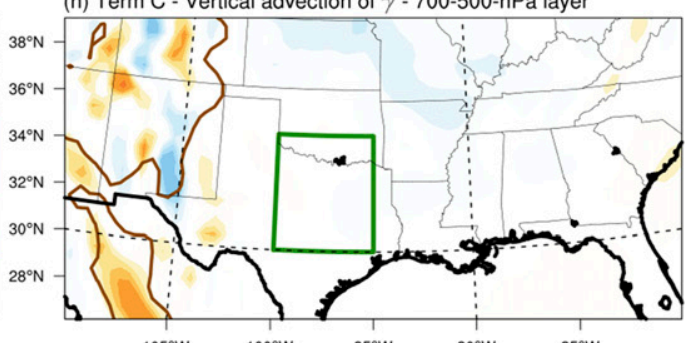

(d) Term D - Differential temperature advection - $600-400-\mathrm{hPa}$ layer
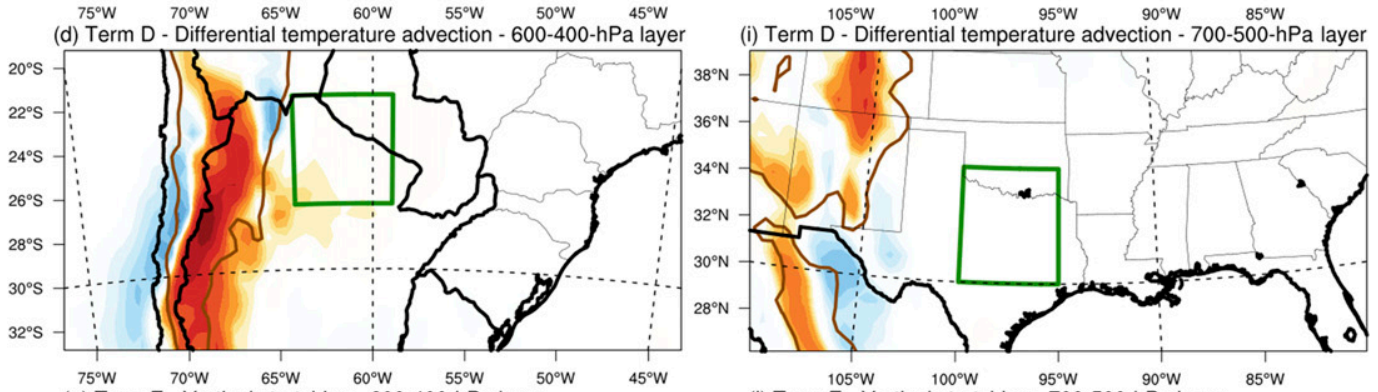

(e) Term E - Vertical stretching - 600-400-hPa layer
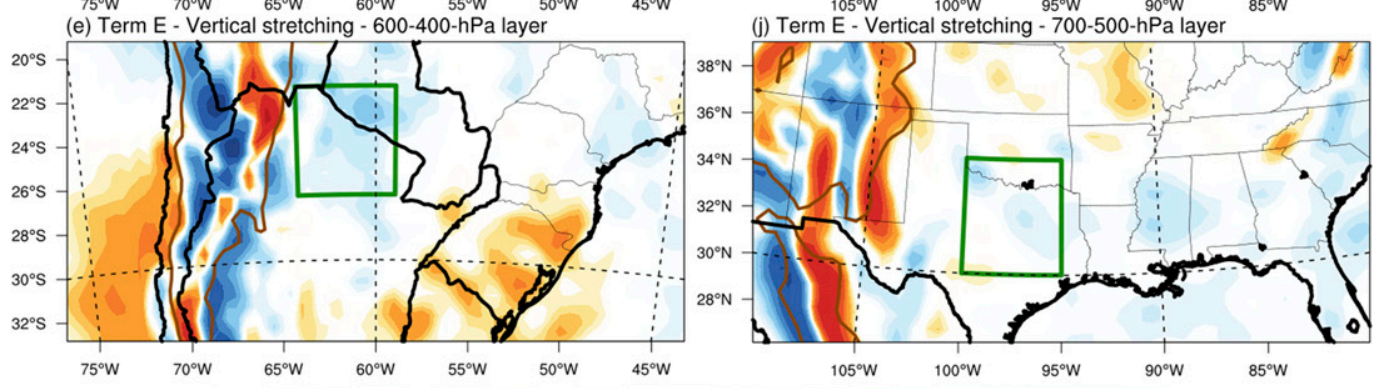

$\begin{array}{lllllllllllllllllllll}-70 & -50 & -30 & -20 & -15 & -10 & -8 & -6 & -4 & -2 & 2 & 4 & 6 & 8 & 10 & 15 & 20 & 30 & 50 & 70\end{array}$

FIG. 9. The $\gamma$ tendency equation (a) term A, (b) term B, (c) term C, (d) term D, and (e) term E in SA, and (f) term $\mathrm{A},(\mathrm{g})$ term $\mathrm{B}$, (h) term $\mathrm{C}$, (i) term $\mathrm{D}$, and (j) term $\mathrm{E}$ in NA $\left(10^{-9} \mathrm{~K} \mathrm{~m}^{-1} \mathrm{~s}^{-1}\right.$, shaded). The terms are calculated from the composite fields of EML cases over R1 of each continent (green squares) during spring, and are averaged over the $600-400-\mathrm{hPa}$ layer in SA and 700-500-hPa layer in NA. The brown contour shows the $1500-\mathrm{m}$ orographic contour. 

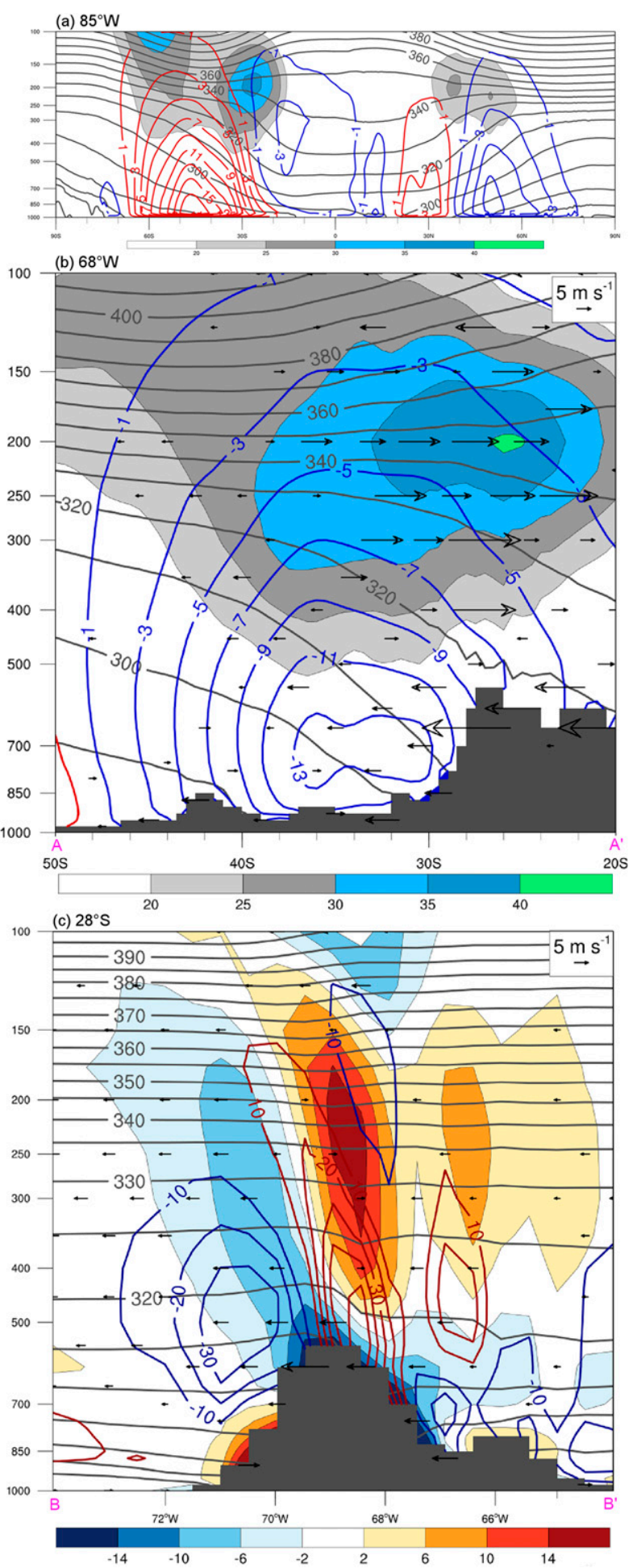

FIG. 10. (a) Cross section from $90^{\circ} \mathrm{S}$ to $90^{\circ} \mathrm{N}$ along $85^{\circ} \mathrm{W}$ of zonal wind magnitude ( $\mathrm{m} \mathrm{s}^{-1}$, shaded), $\Psi_{M}\left[10^{11} \mathrm{~kg} \mathrm{~s}^{-1}\right.$, negative values (anticlockwise circulation) in blue contours every $-2 \times 10^{11} \mathrm{~kg} \mathrm{~s}^{-1}$ starting at $-1 \times 10^{11} \mathrm{~kg} \mathrm{~s}^{-1}$, and positive values (clockwise circulation) in red contours every $2 \times 10^{11} \mathrm{~kg} \mathrm{~s}^{-1}$ starting at $1 \times 10^{11} \mathrm{~kg} \mathrm{~s}^{-1}$ ] and $\theta(\mathrm{K}$, gray contours every $10 \mathrm{~K})$. (b) Cross section of zonal wind magnitude $\left(\mathrm{m} \mathrm{s}^{-1}\right.$, shaded $), \theta(\mathrm{K}$, gray contours every $10 \mathrm{~K})$, of $40^{\circ} \mathrm{S}$ on the cyclonic shear side of the subtropical jet core (Fig. 10b). A comparison of Figs. 10a and 10b reveals that transient synoptic-scale disturbances that cross the Andes can reverse the well-known time-mean Hadley circulation when EMLs are present. Also, the $\mathrm{AA}^{\prime}$ cross section along $68^{\circ} \mathrm{W}$ (Fig. 10b) depicts ageostrophic wind vectors that are oppositely directed to the northward-pointing horizontal $\theta$ gradient below $500 \mathrm{hPa}$ between $20^{\circ}$ and $30^{\circ} \mathrm{S}$. Above $500 \mathrm{hPa}$, the ageostrophic wind vectors point in the direction of the horizontal $\theta$ gradient. Accordingly, the ageostrophic winds beneath the subtropical jet core result in warm-air advection in the 600-500-hPa layer and cold-air advection above $450 \mathrm{hPa}$ with a resulting increase $\gamma$ and a steepening of the midtropospheric lapse rate.

A latitudinal cross section along $28^{\circ} \mathrm{S}\left(\mathrm{BB}^{\prime}\right.$ in Fig. 1a) is shown in Fig. 10c. Low-level northeasterly ageostrophic winds that are located along the eastern Andes foothills are characteristic of a terrain-channeled northerly barrier jet. The approaching upper-level trough (Fig. 6a) induces low-level geopotential height falls east of the Andes (Fig. 8a; Seluchi et al. 2003). The associated terrain-channeled low-level northerly flow accelerates as convergence occurs along the eastern slopes of the Andes. Because the jet-induced thermally direct circulation acts to oppose the observed ageostrophic winds east of the Andes during EML events (Fig. 10b), the terrain-channeled ageostrophic northerly flow east of the Andes and the associated warm advection are the main mechanisms for steepening lapse rates ( $\gamma$ increase).

\section{3) SEVERE WEATHER PARAMETERS}

This section presents an ingredients-based analysis (Johns and Doswell 1992) of environments characterized by the presence of EMLs over the R1-R3 regions. The mechanisms for thunderstorm initiation, dissipation, and the influence of mesoscale circulations are not addressed in this study.

The highest MUCAPE in SA (Figs. 11a-c) is concentrated within the $\mathrm{R} 1-\mathrm{R} 3$ regions in all composites.

\footnotetext{
$\longleftarrow$

$\Psi_{M}\left(10^{11} \mathrm{~kg} \mathrm{~s}^{-1}\right.$, negative values in blue contours every $-2 \times 10^{11} \mathrm{~kg} \mathrm{~s}^{-1}$ starting at $-1 \times 10^{11} \mathrm{~kg} \mathrm{~s}^{-1}$, and positive values in red contours every $2 \times 10^{11} \mathrm{~kg} \mathrm{~s}^{-1}$ starting at $1 \times 10^{11} \mathrm{~kg} \mathrm{~s}^{-1}$ ), and meridional ageostrophic wind ( $\mathrm{m} \mathrm{s}^{-1}$, vectors) along the $\mathrm{AA}^{\prime}$ line $\left(68^{\circ} \mathrm{W}\right)$ in Fig. 1a. (c) Cross section of meridional ageostrophic wind with negative (positive) values denoting northerly (southerly) flow ( $\mathrm{m} \mathrm{s}^{-1}$, shaded), $\theta(\mathrm{K}$, gray contours every $5 \mathrm{~K}), \omega\left[10^{-2} \mathrm{~Pa} \mathrm{~s}^{-1}\right.$, negative values (ascent) in blue contours every $-10 \times 10^{-2} \mathrm{~Pa} \mathrm{~s}^{-1}$, positive values (subsidence) in red contours every $10 \times 10^{-2} \mathrm{~Pa} \mathrm{~s}^{-1}$ ] along the $\mathrm{BB}^{\prime}$ line $\left(28^{\circ} \mathrm{S}\right)$ in Fig. 1a.
} 

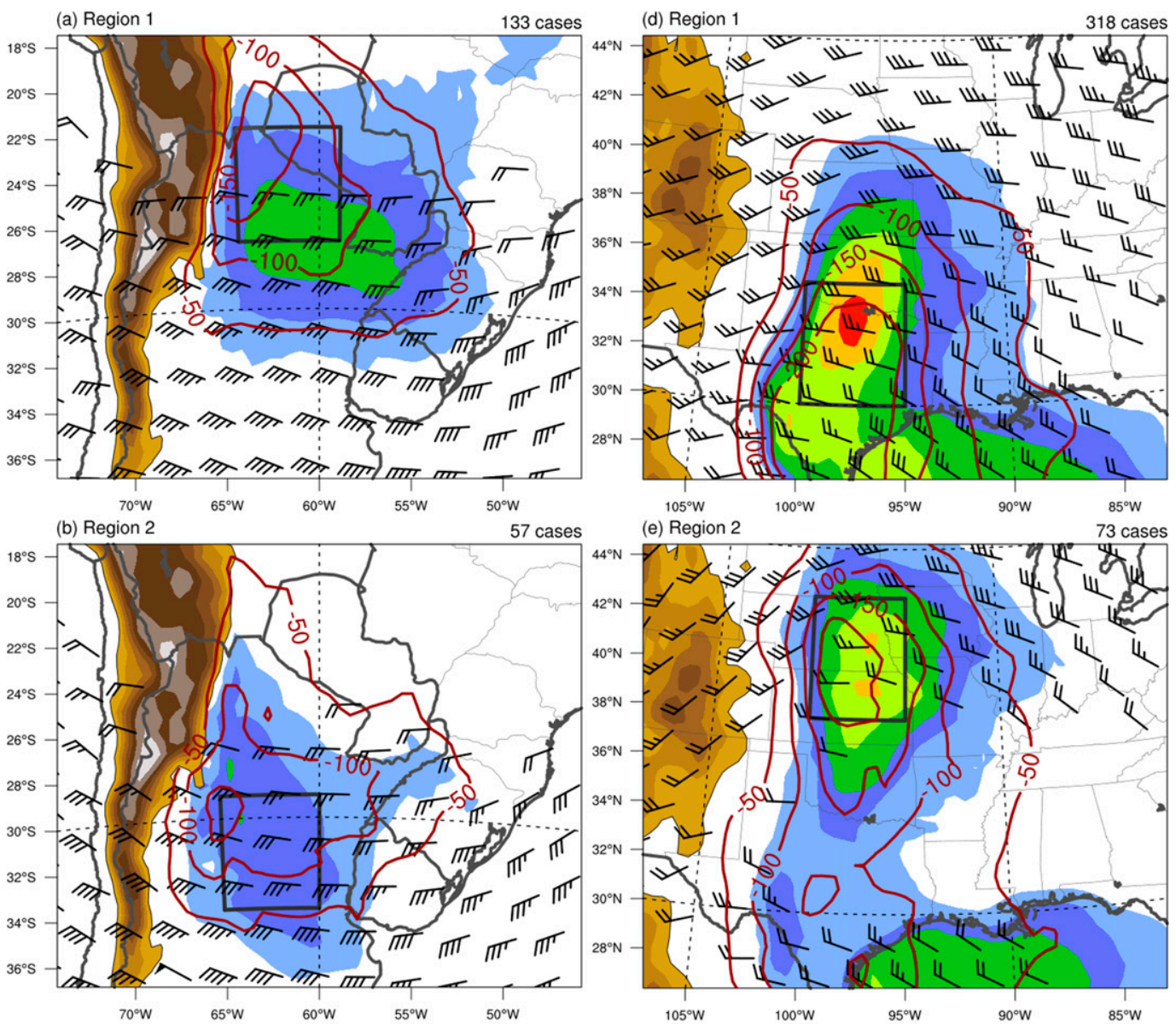

(e) Region
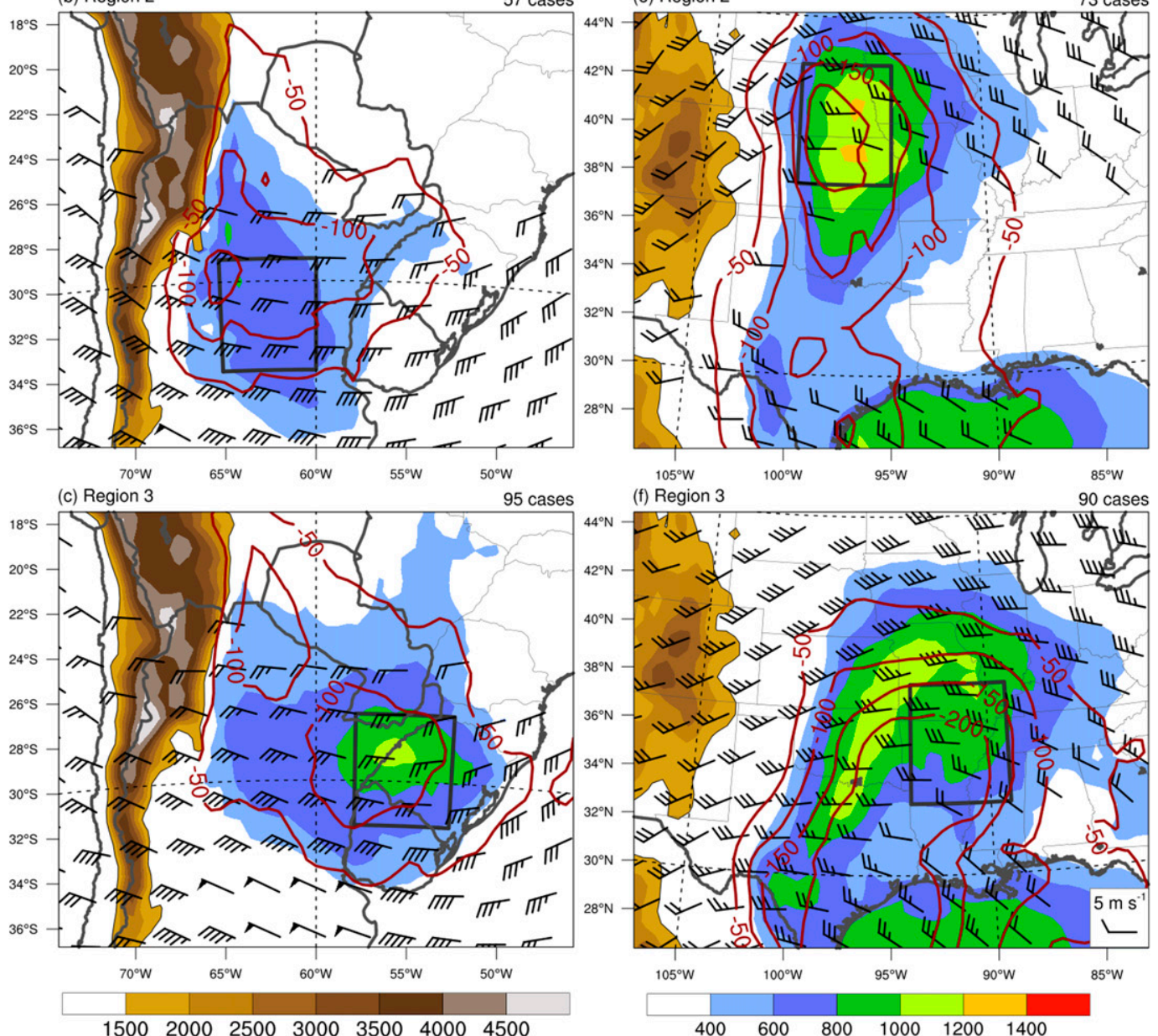

FIG. 11. Composite MUCAPE ( $\mathrm{J} \mathrm{kg}^{-1}$, shaded), 1000-500-hPa wind shear $\left(\mathrm{m} \mathrm{s}^{-1}\right.$, pennant is 25 , full barb is 5, and half barb is $2.5 \mathrm{~m} \mathrm{~s}^{-1}$; only wind barbs greater than $10 \mathrm{~m} \mathrm{~s}^{-1}$ are plotted), and CIN $\left(\mathrm{J} \mathrm{kg}^{-1}\right.$, dark red contours every $-50 \mathrm{~J} \mathrm{~kg}^{-1}$ starting at $-50 \mathrm{~J} \mathrm{~kg}^{-1}$ ) for EML cases in spring in (a) R1, (b) R2, and (c) R3 of SA, and (d) R1, (e) R2, and (f) R3 of NA. Orography is shaded every $500 \mathrm{~m}$ starting at $1500 \mathrm{~m}$. The $5^{\circ} \times 5^{\circ}$ areas are drawn in gray squares. 
MUCAPE is higher over the R3 region (Fig. 11c) because of higher low-level moisture (not shown) than in the R1 and R2 regions (Figs. 11a,b), even though $\gamma$ is lower in R3 (Figs. 7a-c). The 1000-500-hPa wind shear increases poleward and is higher south of the R2 and R3 regions (Figs. 11b,c). The area of greatest ascent poleward of the regions (Figs. 7a-c) is characterized by higher 1000-500-hPa shear but considerably lower MUCAPE than over the R1-R3 regions. The highest CIN values (Figs. 11a-c) are located in the areas where the EMLs have lower base levels and are thicker (Fig. 3a) immediately to the east of the Andes. Reduced CIN values over R3 (Fig. 11c) in association with lower $\gamma$ (Fig. 7c) are likely a result of EML dissipation as it is advected eastward.

MUCAPE distributions in NA composites (Figs. 11d-f) are comparably different from SA (Figs. 11a-c). High MUCAPE is not confined within the R1-R3 regions, but extends from the Gulf of Mexico northward to cover a large area. The northward transport of high- $\theta_{e}$ air by stronger low-level winds in NA (Fig. 8), in association with steeper $\gamma$ in the EML (Fig. 7) in comparison to SA, is responsible for higher values of MUCAPE. The 1000-500-hPa wind shear in NA is lower than in SA due to the weaker upper-level flow during spring (Figs. 3a,e). Poleward of the R1-R3 regions, both in SA and NA (Fig. 11), the 1000-500-hPa wind shear attains the lower threshold for supercell formation $\left(15 \mathrm{~m} \mathrm{~s}^{-1}\right)$ in NA (e.g., Weisman and Klemp 1982; Thompson et al. 2003). CIN in NA composites (Figs. 11d-f) is higher than $200 \mathrm{~J} \mathrm{~kg}^{-1}$ over the R1-R3 regions, whereas CIN only exceeds $100 \mathrm{~J} \mathrm{~kg}^{-1}$ over SA R1-R3 regions (Figs. 11a-c). CIN values of this magnitude in both continents are prohibitive for convective initiation. However, convective initiation is unlikely to occur in the middle of the EML, where CIN is the highest, but rather near its lateral boundaries (Carlson and Ludlam 1968; Keyser and Carlson 1984; LW91). This is the case in the composites, which show ascent (Fig. 7) and MFC (Fig. 8) poleward of the EML location, where CIN is much lower. The presence of moderate CIN also prevents a high number of storms from forming and allows CAPE to increase before convective initiation begins (Bunkers et al. 2010).

The SRH is widely used to estimate the potential for rotating thunderstorms (supercells) in the environment (Droegemeier et al. 1993; Markowski and Richardson 2009). Because SRH values associated with anticyclonic turning winds with height in the Southern Hemisphere are negative, here we will use the SRH magnitude for SA for the sake of comparison with NA.

All composites present $0-3-\mathrm{km}$ SRH (SRH03) greater than $170 \mathrm{~m}^{2} \mathrm{~s}^{-2}$ over and/or near the R1-R3 regions (Fig. 12), with the exception of SA R3 (Fig. 12c). The main difference between SA and NA composites is on SBCAPE values, which are about 2 times higher in NA over the R1-R3 regions. The higher SBCAPE in NA is related to higher relative humidity and dewpoint temperatures in the PBL, as will be shown later, in association with higher $\gamma$ in the EML. Moreover, only over NA is the concomitant occurrence of high values of SBCAPE and SRH03 within the area where the CIN is below $100 \mathrm{~J} \mathrm{~kg}^{-1}$ (Figs. 11d-f) observed.

A greater difference between SA and NA exists in the 0-1-km SRH (SRH01) distribution (Fig. 13). The greater zonal component of 1000-850-hPa wind shear (Fig. 13) over the R1-R3 regions in NA is related to a more rapid anticyclonic turning of the winds with height and higher SRH01 over NA, as will be shown later. The LCL height distribution in SA is marked by high LCLs near the Andes and in northern Argentina, Paraguay, and Bolivia, and heights below $1000 \mathrm{~m}$ only in southern Brazil and Uruguay. The highest SRH01 values are collocated with LCL heights below $1000 \mathrm{~m}$ in all NA composites [in particular over NA R1 (Fig. 13d)], indicating an environment with very low cloud bases and high SRH in the PBL. These parameters also suggest that thunderstorms forming in such environments, where synoptic-scale ascent and MFC are present (Figs. 7 and 8), have a higher likelihood of generating tornadoes near NA regions, where a combination of higher SRH01 and SBCAPE and lower LCL heights occurs (Thompson et al. 2003).

\section{4) SOUNDINGS AND HODOGRAPHS}

Composite soundings and hodographs were generated by using the grid point in the middle of the $5^{\circ} \times 5^{\circ}$ areas of the R1-R3 regions (Fig. 14). The composite soundings and hodographs averaged over the $5^{\circ} \times 5^{\circ}$ areas (not shown) give very similar results. The EML is evident in the temperature profile (Figs. 14a,b): its height varies between SA and NA, corroborating what was discussed in section 3a. Composite soundings in SA (Fig. 14a) show steep $\gamma$ in the EML above a layer with less steep $\gamma$ between 700 and $600 \mathrm{hPa}$. The temperature inversion is better characterized in R1 (Fig. 14a), resulting in higher CIN in this location (Fig. 11a). In NA (Fig. 10b), the temperature inversion is clearer between 850 and $750 \mathrm{hPa}$. CFSR has difficulty in representing the temperature inversion in the base of EMLs (Fig. 2).

The low-level temperature/dewpoint temperature profiles in SA (Fig. 14a) exhibit an inverted V shape with relative humidity decreasing from $700 \mathrm{hPa}$ to the surface, particularly in R1. Greater relative humidity is found near the surface in NA (Fig. 14b). The moist lowlevel layer in NA is much shallower than in SA, extending from surface to about $900 \mathrm{hPa}$, above which the 
(a) Region 1

133 cases

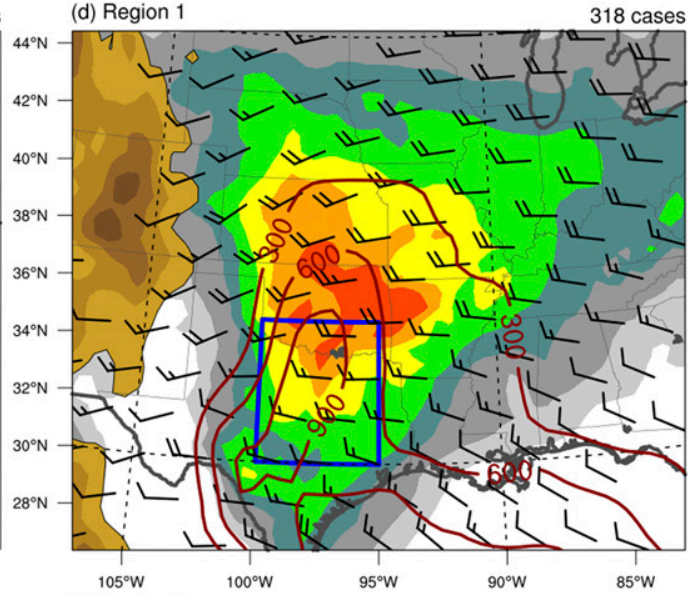

(d) Region 1

318 cases
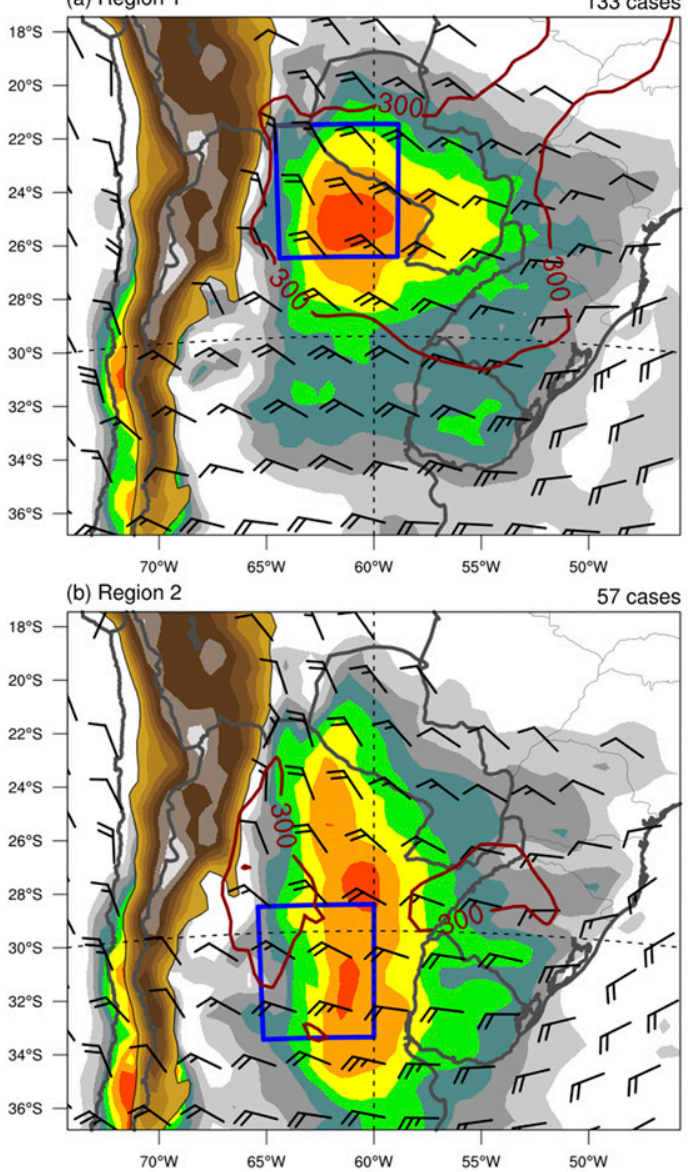

(e) Region 2
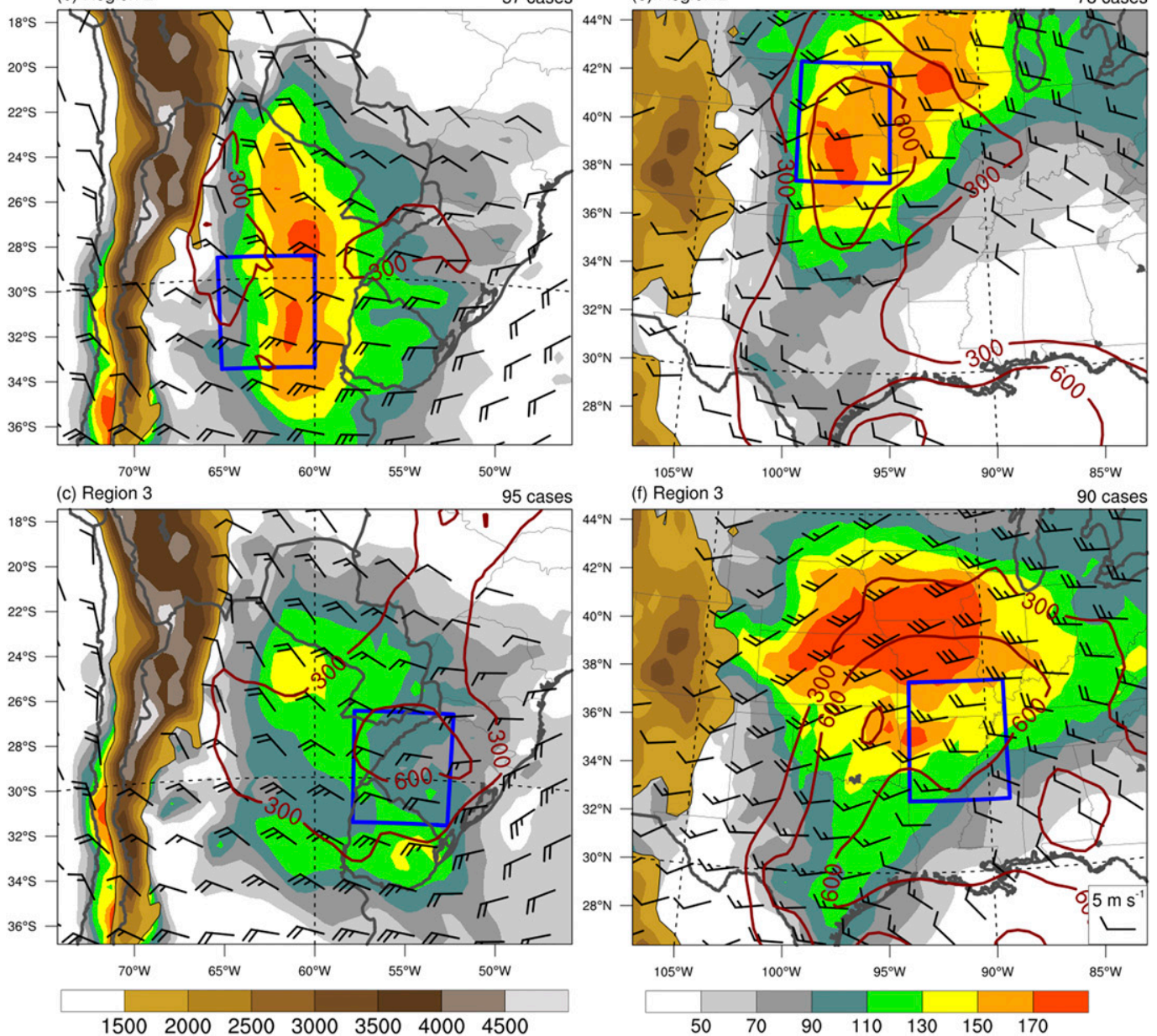

FIG. 12. Composite 0-3-km SRH magnitude ( $\mathrm{m}^{2} \mathrm{~s}^{-2}$, shaded), 1000-700-hPa wind shear ( $\mathrm{m} \mathrm{s}^{-1}$, pennant is 25 , full barb is 5 , and half barb is $2.5 \mathrm{~m} \mathrm{~s}^{-1}$; only wind barbs greater than $5 \mathrm{~m} \mathrm{~s}^{-1}$ are plotted), and SBCAPE $\left(\mathrm{J} \mathrm{kg}^{-1}\right.$, red contours every $300 \mathrm{~J} \mathrm{~kg}^{-1}$ starting at $300 \mathrm{~J} \mathrm{~kg}^{-1}$ ) for EML cases in spring in (a) R1, (b) R2, and (c) R3 of SA, and (d) R1, (e) R2, and (f) R3 of NA. Orography is shaded every $500 \mathrm{~m}$ starting at $1500 \mathrm{~m}$. The $5^{\circ} \times 5^{\circ}$ areas are drawn in blue squares. 

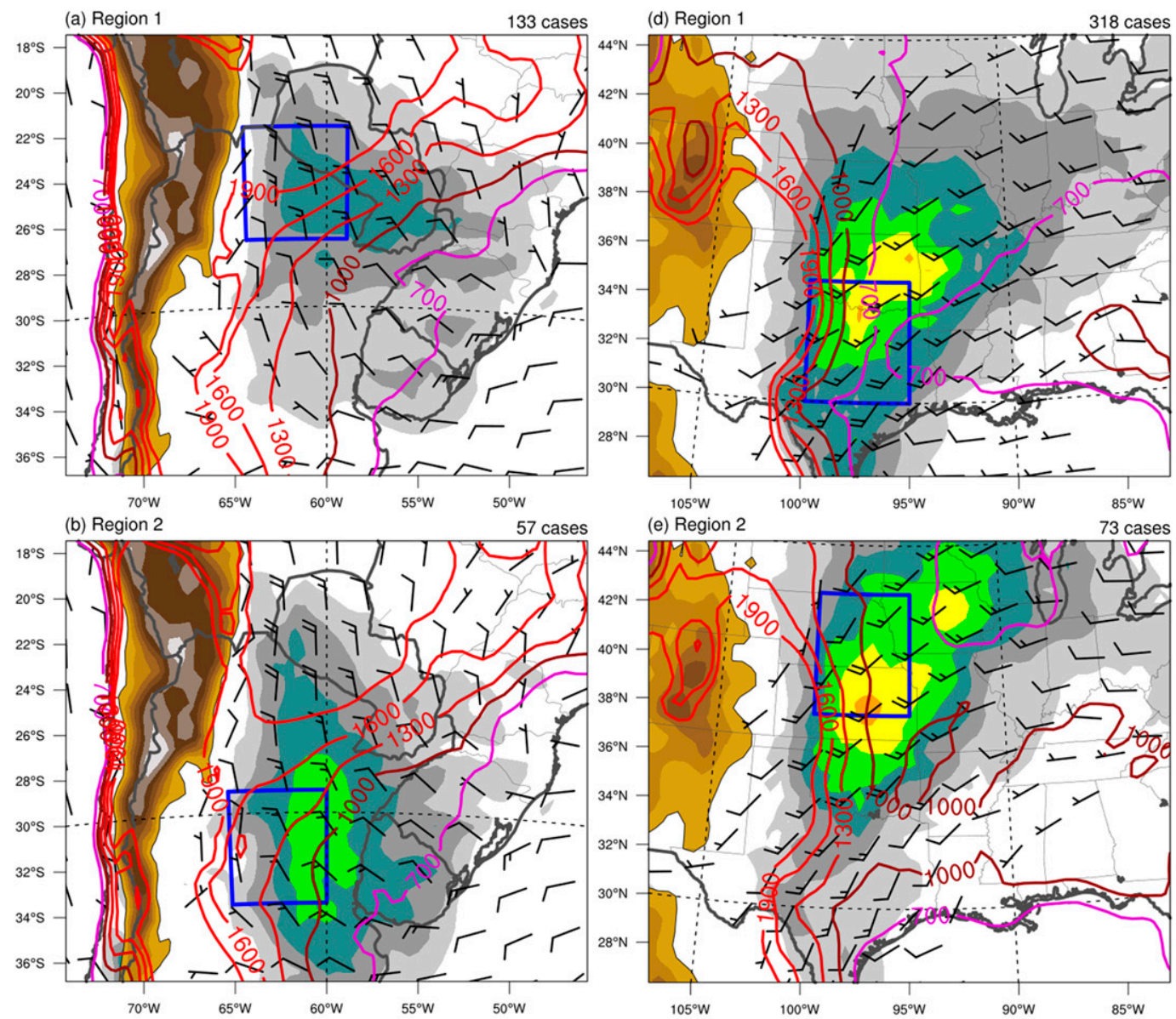

(e) Region 2
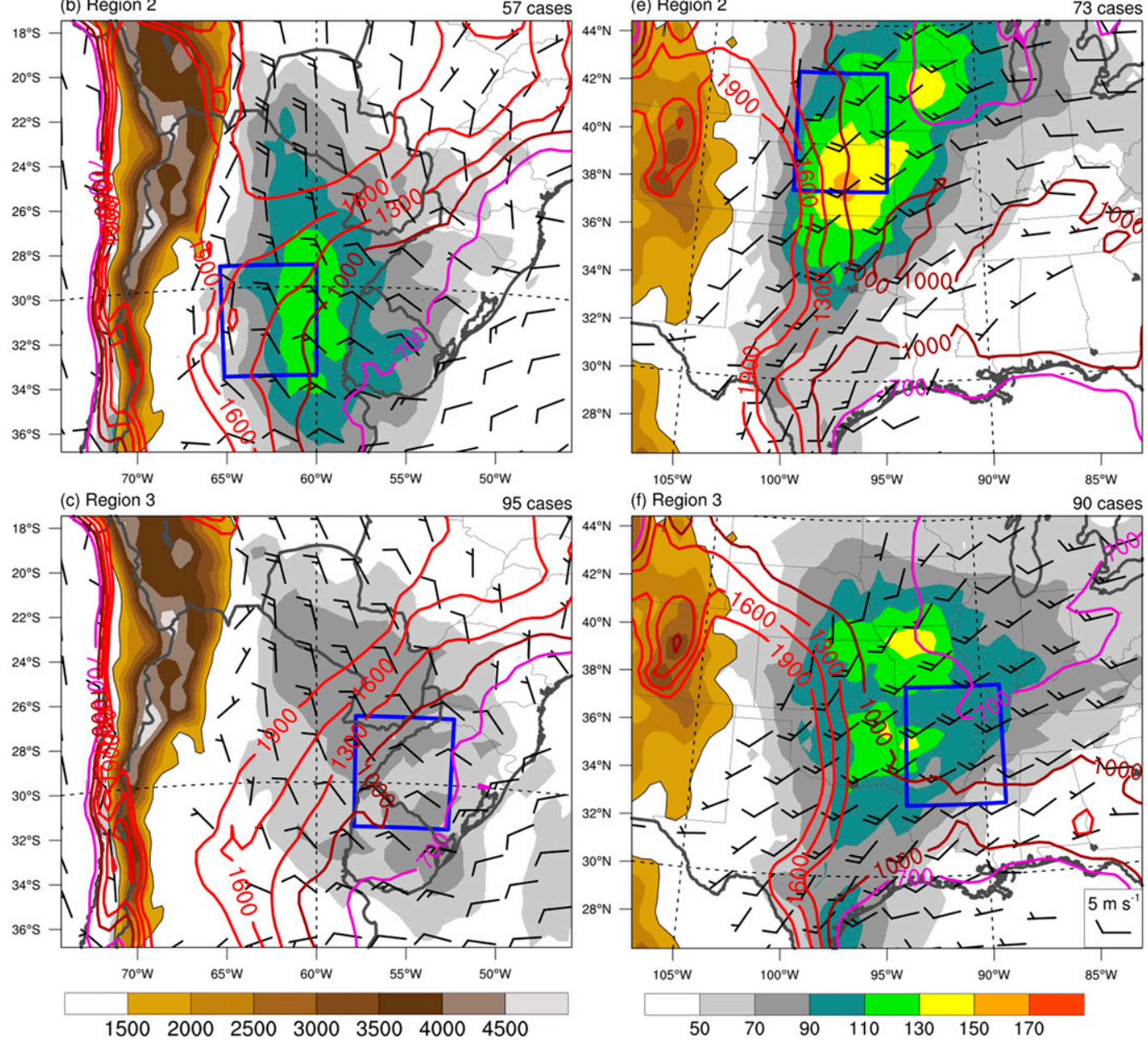

FIG. 13. Composite 0-1-km SRH magnitude $\left(\mathrm{m}^{2} \mathrm{~s}^{-2}\right.$, shaded), 1000-850-hPa wind shear ( $\mathrm{m} \mathrm{s}^{-1}$, pennant is 25 , full barb is 5 , and half barb is $2.5 \mathrm{~m} \mathrm{~s}^{-1}$; only wind barbs greater than $2.5 \mathrm{~m} \mathrm{~s}^{-1}$ are plotted), and LCL height ( $\mathrm{m}$, colored contours every $300 \mathrm{~m}$ starting at $700 \mathrm{~m}$ ) for EML cases in spring in (a) R1, (b) R2, and (c) R3 of SA, and (d) R1, (e) R2, and (f) R3 of NA. Orography is shaded every $500 \mathrm{~m}$ starting at $1500 \mathrm{~m}$. The $5^{\circ} \times 5^{\circ}$ areas are drawn in blue squares. 

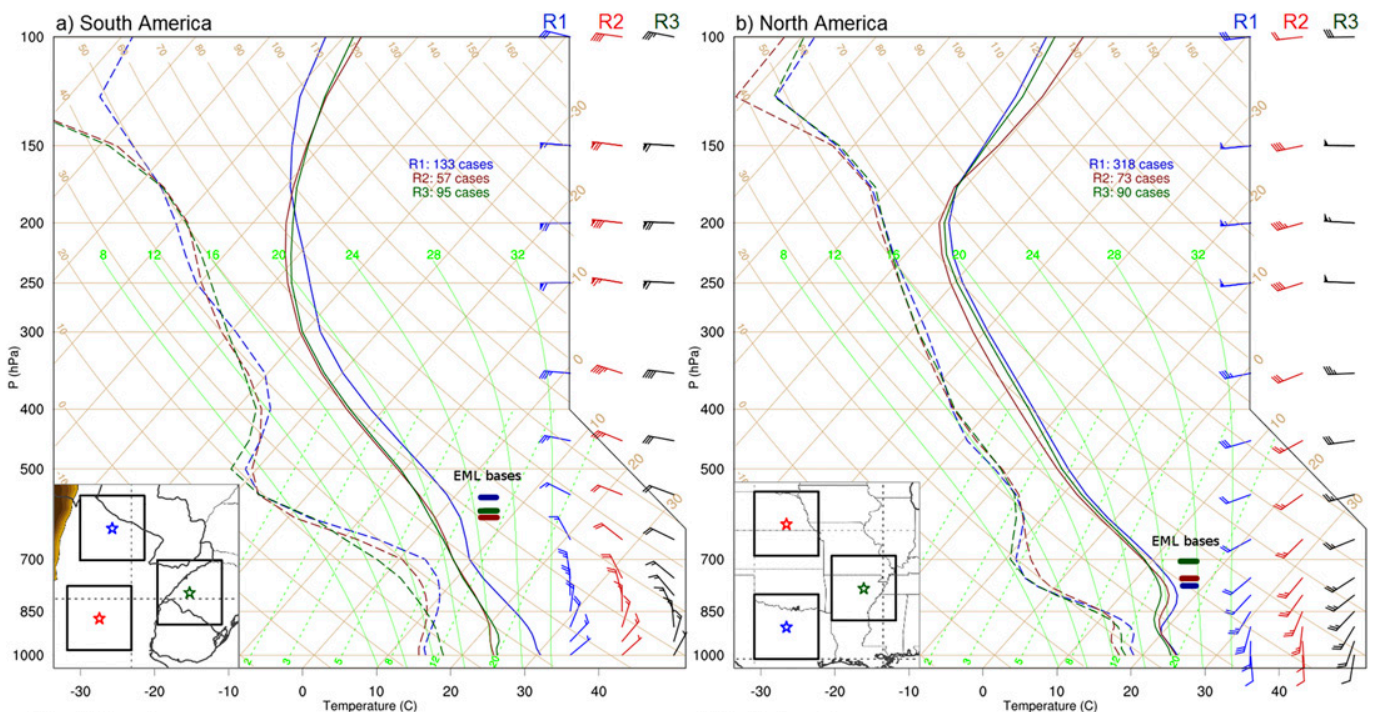

c) South America
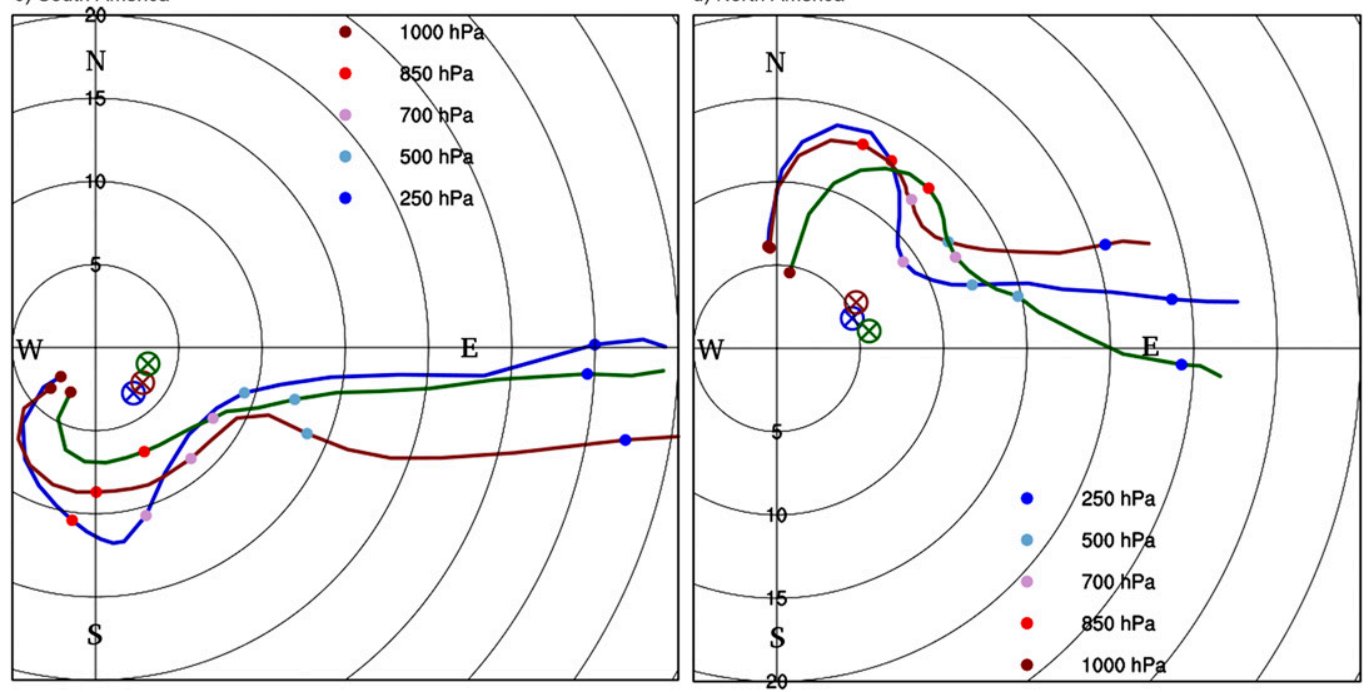

FIG. 14. Composite soundings and hodographs for R1 (blue lines), R2 (red lines), and R3 (green lines) of (a), (c) SA and (b),(d) NA in spring. The colored stars in the maps are the locations of the soundings and hodographs in the middle of the $5^{\circ} \times 5^{\circ}$ areas. EML bases are indicated by colored dashes for each sounding. In the hodographs, storm motion is represented by the operator symbols with the same colors, circles of same wind speed are shown every $5 \mathrm{~m} \mathrm{~s}^{-1}$, and the dark red, red, magenta, light blue, and blue dots mark the 1000-, 850-, 700-, 500-, and 250-hPa levels, respectively.

drier air associated with the EML resides. Higher relative humidity due to lower temperature and higher dewpoint temperature in NA composite soundings is related to lower LCL height (Figs. 13c-e), which is an important characteristic observed in environments favoring tornadic thunderstorms (e.g., Rasmussen and Blanchard 1998; Thompson et al. 2003). The closer proximity of NA R1-R3 regions to the main moisture source (Gulf of Mexico) is one of the reasons for higher low-level RH in comparison to SA.

The composite hodographs in SA (Fig. 14c) exhibit anticyclonic turning of the winds from surface to nearly
$700 \mathrm{hPa}$, indicating warm advection in this layer (Fig. 8). The higher SRH in NA (Figs. 12 and 13) is due to stronger poleward flow at $1000 \mathrm{hPa}$ in association with stronger zonal component of the flow in 850 and $700 \mathrm{hPa}$, favoring a more pronounced anticyclonic turning of the winds with height in comparison with SA. In SA, the high elevation of the Andes precludes westerly low-level winds, in particular over R1 and R2 (Figs. 8a,b). SA R3 composite hodographs (Fig. 14c) depict stronger low-level zonal winds than R1-R2 composites because of the greater distance from the 
Andes, but the weaker meridional low-level winds cause lower SRH values relative to R1 and R2 composites (Figs. 12a-c and 13a-c).

\section{5) BoXPLOTS}

Figure 15 shows boxplots of the distributions of the severe weather parameters (described in section 2c) for each region. The NA MUCAPE distribution (Fig. 15a) exhibits higher values of almost all statistical parameters when comparing a given region with its SA counterpart. A greater difference exists between both continents in the SBCAPE distributions (Fig. 15e), with considerably higher values in the NA regions. Both MUCAPE and SBCAPE differences between SA and NA are statistically significant (95\% confidence) for R1 and R2. The lower EML bases in NA relate to CIN values nearly twice as large in SA (Fig. 15b). The LCL heights (Fig. 15f) in SA are relatively higher than in NA, except in R3. These distributions corroborate Figs. 9 and 10, showing lower mean LCL heights in NA and higher frequency of environments having LCL heights favorable for tornadic storms (Rasmussen and Blanchard 1998; Thompson et al. 2003).

Little difference exists between the distributions of 1000-850-hPa wind shear in SA and NA (Fig. 15c), despite relatively lower values in SA R3, which relates to lower SRH01 in this region (Fig. 15d). The 1000-500-hPa wind shear (Fig. 15g) is higher in NA R1 and SA R2. The average $1000-500-\mathrm{hPa}$ wind shear is higher in SA poleward of the EML location (Fig. 11), where the ascent is greater (Fig. 7).

The SRH03 distributions (Fig. 15h) are very similar among continents, but the SRH01 distributions (Fig. 15d) exhibit higher (and statistically significant) values in NA. The SRH03 and SRH01 composite fields (Figs. 12 and 13) show that even higher SRH values are found poleward of the NA regions, not inside the $5^{\circ} \times 5^{\circ}$ areas. Corroborating what the composite fields have shown (Figs. 12 and 13), R2 of SA has SRH comparable to NA regions (Fig. 15d) but considerably lower SBCAPE (Fig. 15e), which limits the likelihood for surface-based supercells and tornado occurrence for convective initiation occurring in these environments (Brooks et al. 2003; Smith et al. 2012; Thompson et al. 2012), based on the available ingredients.

The conclusions associated with Figs. 11-15 are based on Smith et al. (2012) and Thompson et al. (2012), which show how the severe weather parameters link with convective modes and severe weather hazards. The present study is the first to relate the severe weather parameters with EMLs in SA and NA and to compare the parameters between both continents.

\section{Conclusions}

This paper presented a climatology of EMLs in NA and SA based on CFSR data. The method to identify EMLs was based on the occurrence of an elevated, 150 -hPa-thick layer having at least $7.5 \mathrm{~K} \mathrm{~km}^{-1}$ of $\gamma$. The average characteristics of the EMLs, its seasonal variability, and the synoptic-scale environments associated with EMLs were analyzed.

EML occurrence in SA peaks in winter in southern Paraguay and northeastern Argentina and exhibits a minimum during summer in western Argentina. EML formation occurs in the anticyclonic shear side of the upper-level jet and follows the jet seasonal meridional displacement. SA EMLs form due to ageostrophic circulations east of the Andes, mainly the terrainchanneled northerly flow caused by the lee low pressure system ahead of the approaching upper-level trough, which increases $\gamma$ by differential ageostrophic temperature advection. Greater baroclinicity during the cold season in SA enhances the effects of ageostrophic circulations in the $\gamma$ change and explains the higher frequency of EMLs east of the Andes from fall to spring. In NA, EML occurrence follows the maximum solar radiation over the higher terrain, with the maximum frequency in spring migrating northward in summer, similarly to the findings of other studies (e.g., LW91). The lower height of the Rockies in NA, as compared to the Andes, is responsible for EML bases nearly $100 \mathrm{hPa}$ lower in NA because the $\gamma$-increase mechanisms are coupled to the mountain ranges in both continents. Greater EML thicknesses are found in spring and summer in NA but during winter in SA. The formation of surface-based mixed layers through radiative heating over high terrain causes the EML characteristics over NA to be more homogeneous and less variable as the EML is advected away from the Rockies. On the other hand, SA EML characteristics are more heterogeneous due to the ageostrophic circulations responsible for $\gamma$ increase (terms $\mathrm{C}, \mathrm{D}$, and $\mathrm{E}$ ), which are characterized by localized maxima and minima in the $\gamma$ tendency field. It is important to note, however, that the estimation of the $\gamma$ tendency equation terms based on composites of EML cases is not the most accurate method to study the EML formation processes. An analysis of the terms along EML parcels trajectories, followed by a statistical analysis of the magnitude of each term, may provide more reliable results and is a suggestion for future studies. Another suggestion is the use of idealized numerical modeling to study EML formation mechanisms.

Synoptic conditions associated with EML occurrence in both continents are characterized by an anomalous 

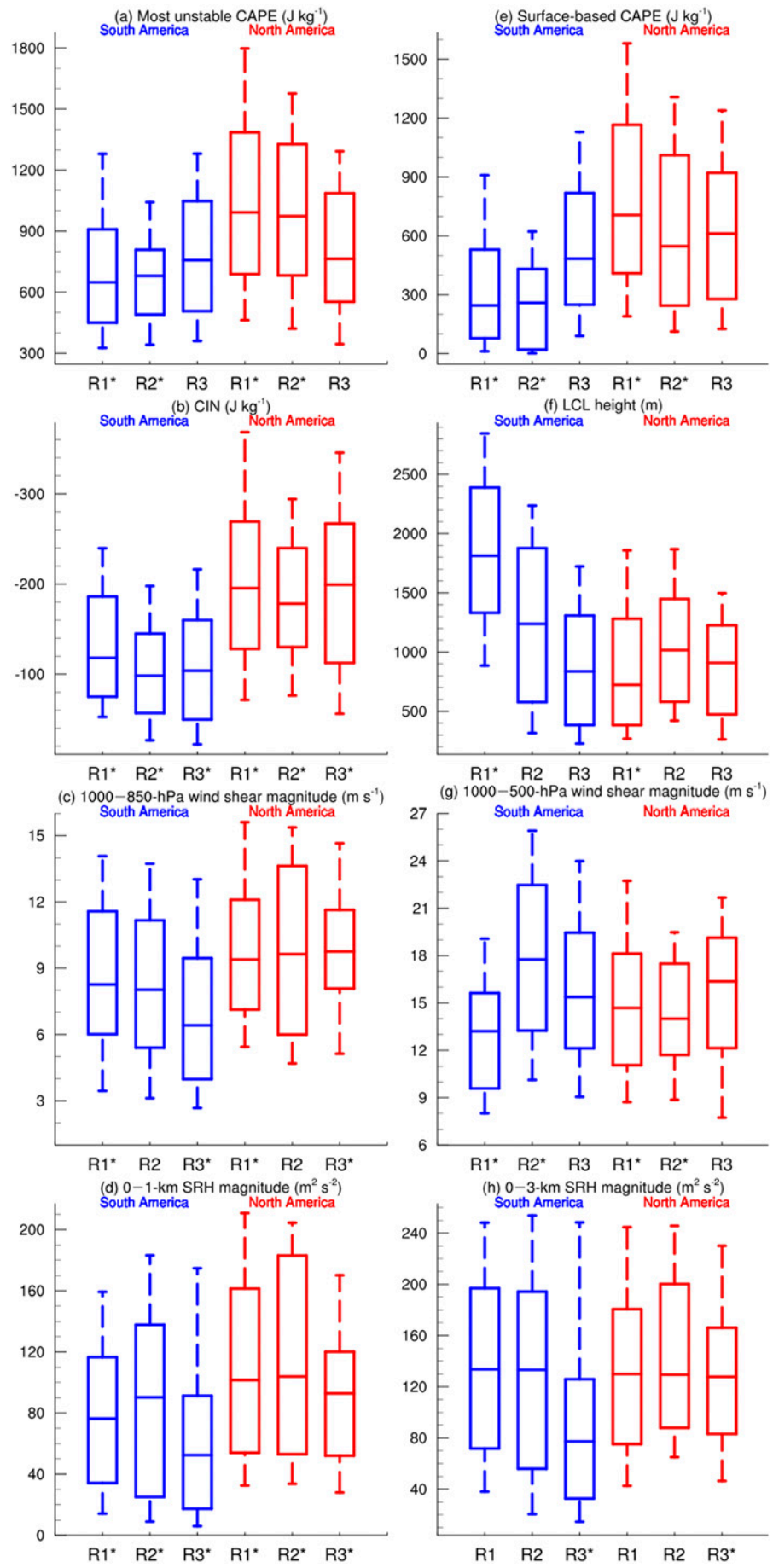

FIG. 15. Boxplots of the distributions of (a) MUCAPE ( $\left.\mathrm{J} \mathrm{kg}^{-1}\right)$, (b) CIN $\left(\mathrm{J} \mathrm{kg}^{-1}\right)$, (c) 1000-850-hPa wind shear magnitude $\left(\mathrm{m} \mathrm{s}^{-1}\right)$, (d) $0-1-\mathrm{km}^{-}$ SRH magnitude $\left(\mathrm{m}^{2} \mathrm{~s}^{-2}\right)$, (e) SBCAPE $\left(\mathrm{J} \mathrm{kg}^{-1}\right)$, (f) LCL height (m), (g) 1000-500-hPa wind shear magnitude $\left(\mathrm{m} \mathrm{s}^{-1}\right)$, and (h) 0-3-km SRH magnitude $\left(\mathrm{m}^{2} \mathrm{~s}^{-2}\right)$ over the R1-R3 regions of SA (blue boxplots) and NA (red boxplots) in EML cases during spring. Statistical parameters in the boxplot are the 90th and 10th percentiles (upper and lower tick marks, respectively), 75th and 25th percentiles (upper and lower box boundaries, respectively), and median (line inside the boxes). Parameters that present statistically significant ( $95 \%$ confidence) differences between the same regions in the continents are marked with an asterisk in the $x$ axis. Details about the construction of the boxplots are found in the text. 
upper-level trough over the mountain ranges and an anomalous ridge downstream, which favors a southwesterly upper-level flow over the R1-R3 regions of NA and northwesterly flow over SA. The MFC associated with meridional $\theta_{e}$ gradient and ascent poleward of the $\mathrm{R} 1-\mathrm{R} 3$ regions indicates warm-front activity in this area. The amplitude of the upper-level flow is greater when EMLs occur at higher latitudes (over R2), which induces stronger poleward-directed low-level flow east of the mountains. EMLs advected farther east (over R3) present lower $\gamma$ decrease in NA in comparison to SA, which is attributed to lower vertical $\gamma$ advection and stretching (terms $\mathrm{C}$ and $\mathrm{E}$ ) in NA because $\gamma$ is higher. R3 in both continents is also characterized by greater zonal component of the low-level flow and consequently lower SRH, particularly over SA. The southwesterly upperlevel flow regime in NA has been described by LW91 as the most common configuration for EML formation, but other synoptic flow regimes are related to EML occurrence. The composites in this paper do not deal with the different synoptic conditions that favor EMLs in SA and their seasonal variability but provide a starting point for further studies on this theme. Climatological studies of EMLs in other parts of the world, such as near the Tibetan Plateau, are suggested.

Deep-layer shear is higher in SA in comparison to NA in general, due to the climatologically stronger upperlevel jet in SA. However, greater PBL moisture superposed by higher $\gamma$ causes both MUCAPE and SBCAPE to be higher in NA where EMLs occur, and there is a better collocation of the high-CAPE plume with high values of SRH, mainly in the $0-1-\mathrm{km}$ layer. NA composites also present lower LCL heights due to higher relative humidity in the lowest levels above the ground. Composite hodographs for NA regions have stronger winds from 1000 to $850 \mathrm{hPa}$ and a more rapid anticyclonic turning with height in comparison to SA composites, which explains the higher SRH in general. The distributions of the severe weather parameters suggest a higher likelihood for supercells and tornadoes to form in NA in EML environments.

Some concerns about this research must be kept in mind. Brooks et al. (2003) point out that the analysis of severe weather environments based entirely on the available ingredients (Johns and Doswell 1992) might be missing important information. Reanalyses do not characterize mesoscale boundaries correctly, and research has shown that these boundaries are very important to the generation and modification of existing vorticity in the environment, allowing mesocyclogenesis and tornadogenesis to occur (e.g., Markowski and Richardson 2009). The storm initiation mechanisms are also very important in the evolution of severe thunderstorms. The lack of a severe weather report database in SA hinders more conclusive results regarding the association of the EML environments with severe thunderstorms (Nascimento and Doswell 2006). Recently, Nesbitt et al. (2016) and Rasmussen and Houze $(2011,2016)$ presented evidence of the occurrence of squall lines and supercells in western Argentina (in some occasions associated with EMLs), but a long climatological study that associates the environmental conditions with observed severe storm reports is necessary in SA.

We hope that future field campaigns, like the RELAMPAGO Project (https://publish.illinois.edu/ relampago/) in northwestern Argentina, scheduled for November-December 2018, will elucidate some aspects of EML formation near the Andes and their relation with severe thunderstorms in the region by using an observational network instead of reanalysis data. Also, there is an evident need for improvement of SA soundings network, mainly in areas in northern Argentina, Paraguay, and Bolivia. Soundings in these areas will capture important features in the severe weather environments east of the Andes, such as the low-level jet and the EML, improving forecasts and increasing our understanding of the weather in this region.

Acknowledgments. The first author acknowledges support from CNPq-Ciência Sem Fronteiras program (233142/2014-2), from Brazil, and the Department of Atmospheric and Environmental Sciences of the University at Albany for the research and computational support. The second author acknowledges research support from NSF Grant AGS-1240502. We acknowledge the editor and three anonymous reviewers for their enormous contributions to the quality of this paper.

\section{REFERENCES}

Anabor, V., D. J. Stensrud, and O. L. de Moraes, 2008: Serial upstream-propagating mesoscale convective system events over southeastern South America. Mon. Wea. Rev., 136, 30873105, https://doi.org/10.1175/2007MWR2334.1.

Banacos, P. C., and D. M. Schultz, 2005: The use of moisture flux convergence in forecasting convective initiation: Historical and operational perspectives. Wea. Forecasting, 20, 351-366, https://doi.org/10.1175/WAF858.1.

— layer with significant severe weather events in the northeastern United States. Wea. Forecasting, 25, 1082-1102, https://doi. org/10.1175/2010WAF2222363.1.

Bao, X., and F. Zhang, 2013: Evaluation of NCEP-CFSR, NCEPNCAR, ERA-Interim, and ERA-40 reanalysis datasets against independent sounding observations over the Tibetan Plateau. J. Climate, 26, 206-214, https://doi.org/10.1175/ JCLI-D-12-00056.1. 
Brooks, H. E., J. W. Lee, and J. P. Craven, 2003: The spatial distribution of severe thunderstorm and tornado environments from global reanalysis data. Atmos. Res., 67-68, 73-94, https:// doi.org/10.1016/S0169-8095(03)00045-0.

Bunkers, M. J., J. R. Wetenkamp Jr., J. J. Schild, and A. Fischer, 2010: Observations of the relationship between 700-mb temperatures and severe weather reports across the contiguous United States. Wea. Forecasting, 25, 799-814, https://doi.org/ 10.1175/2009WAF2222333.1.

Carlson, T. N., and F. H. Ludlam, 1968: Conditions for the occurrence of severe local thunderstorms. Tellus, 20, 203-226, https://doi.org/10.3402/tellusa.v20i2.10002.

Chen, G., T. Iwasaki, H. Qin, and W. Sha, 2014: Evaluation of the warm-season diurnal variability over East Asia in recent reanalyses JRA-55, ERA-Interim, NCEP CFSR, and NASA MERRA. J. Climate, 27, 5517-5537, https://doi.org/10.1175/ JCLI-D-14-00005.1.

Cordeira, J. M., N. D. Metz, M. E. Howarth, and T. J. Galarneau Jr., 2017: Multiscale upstream and in situ precursors to the elevated mixed layer and high-impact weather over the Midwest United States. Wea. Forecasting, 32, 905-923, https:// doi.org/10.1175/WAF-D-16-0122.1.

Das, S., and Coauthors, 2014: The SAARC STORM: A coordinated field experiment on severe thunderstorm observations and regional modeling over the South Asian region. Bull. Amer. Meteor. Soc., 95, 603-617, https://doi.org/10.1175/ BAMS-D-12-00237.1.

Davies, J. M., and R. H. Johns, 1993: Some wind and instability parameters associated with strong and violent tornadoes: 1 . Wind shear and helicity. The Tornado: Its Structure, Dynamics, Prediction, and Hazards, Geophys. Monogr., Vol. 79, Amer. Geophys. Union, 573-582, https://doi.org/10.1029/ GM079p0573.

Droegemeier, K. K., S. M. Lazarus, and R. Davies-Jones, 1993: The influence of helicity on numerically simulated convective thunderstorms. Mon. Wea. Rev., 121, 2005-2029, https://doi.org/ 10.1175/1520-0493(1993)121<2005:TIOHON > 2.0.CO;2.

Johns, R. H., and C. A. Doswell, 1992: Severe local storms forecasting. Wea. Forecasting, 7, 588-612, https://doi.org/10.1175/ 1520-0434(1992)007<0588:SLSF $>2.0 . C O ; 2$.

Keyser, D., and T. N. Carlson, 1984: Transverse ageostrophic circulations associated with elevated mixed layers. Mon. Wea. Rev., 112, 2465-2478, https://doi.org/10.1175/ 1520-0493(1984)112<2465:TACAWE > 2.0.CO;2.

Lanicci, J. M., and T. T. Warner, 1991a: A synoptic climatology of the elevated mixed-layer inversion over the southern Great Plains in spring. Part I: Structure, dynamics, and seasonal evolution. Wea. Forecasting, 6, 181-197, https://doi.org/ 10.1175/1520-0434(1991)006<0181:ASCOTE >2.0.CO;2.

_ and 1991b: A synoptic climatology of the elevated mixed-layer inversion over the southern Great Plains in spring. Part II: The life cycle of the lid. Wea. Forecasting, 6, 198-213, https://doi.org/10.1175/1520-0434(1991)006<0198:ASCOTE > 2.0. $\mathrm{CO} ; 2$.

— mixed-layer inversion over the southern Great Plains in spring. Part III: Relationship to severe-storms climatology. Wea. Forecasting, 6, 214-226, https://doi.org/10.1175/15200434(1991)006<0214:ASCOTE > 2.0.CO;2.

Lawrence, M. G., 2005: The relationship between relative humidity and the dewpoint temperature in moist air: A simple conversion and applications. Bull. Amer. Meteor. Soc., 86, 225-233, https://doi.org/10.1175/BAMS-86-2-225.
Machado, L. A. T., W. B. Rossow, R. L. Guedes, and A. W. Walker, 1998: Life cycle variations of mesoscale convective systems over the Americas. Mon. Wea. Rev., 126, 1630-1654, https://doi.org/ 10.1175/1520-0493(1998)126<1630:LCVOMC > 2.0.CO;2.

Markowski, P. M., and Y. P. Richardson, 2009: Tornadogenesis: Our current understanding, forecasting considerations, and questions to guide future research. Atmos. Res., 93, 3-10, https://doi.org/10.1016/j.atmosres.2008.09.015.

Nascimento, E. L., and C. A. Doswell III, 2006: The need for an improved documentation of severe thunderstorms and tornadoes in South America. Symp. on the Challenges of Severe Convective Storms, Atlanta, GA, Amer. Meteor. Soc., P1.18, https://ams. confex.com/ams/Annual2006/techprogram/paper_102247.htm.

Nesbitt, S. W., P. Borque, K. L. Rasmussen, P. Salio, R. J. Trapp, L. Vidal, M. Rugna, and J. Mulholland, 2016: Severe convection in central Argentina: Storm modes and environments. 28th Conf. on Severe Local Storms, Portland, OR, Amer. Meteor. Soc., 7A.6, https://ams.confex.com/ams/28SLS/ webprogram/Paper301960.html.

Qin, Y., P. Wang, Z. Guan, and Y. Yue, 2006: Comparison of the Hadley cells calculated from two reanalysis data sets. Chin. Sci. Bull., 51, 1741-1746, https://doi.org/10.1007/s11434-006-2030-3.

Rasmussen, E. N., and D. O. Blanchard, 1998: A baseline climatology of sounding-derived supercell and tornado forecast parameters. Wea. Forecasting, 13, 1148-1164, https://doi.org/ 10.1175/1520-0434(1998)013<1148:ABCOSD>2.0.CO;2.

Rasmussen, K. L., and R. A. Houze Jr., 2011: Orogenic convection in subtropical South America as seen by the TRMM satellite. Mon. Wea. Rev., 139, 2399-2420, https://doi.org/10.1175/ MWR-D-10-05006.1.

— , and - 2016: Convective initiation near the Andes in subtropical South America. Mon. Wea. Rev., 144, 2351-2374, https://doi.org/10.1175/MWR-D-15-0058.1.

Saha, S., and Coauthors, 2010: The NCEP Climate Forecast System Reanalysis. Bull. Amer. Meteor. Soc., 91, 1015-1058, https:// doi.org/10.1175/2010BAMS3001.1.

Salio, P., M. Nicolini, and E. J. Zipser, 2007: Mesoscale convective systems over southeastern South America and their relationship with the South American low-level jet. Mon. Wea. Rev., 135, 1290-1309, https://doi.org/10.1175/MWR3305.1.

Seluchi, M. E., A. C. Saulo, M. Nicolini, and P. Satyamurty, 2003: The northwestern Argentinean low: A study of two typical events. Mon. Wea. Rev., 131, 2361-2378, https://doi.org/ 10.1175/1520-0493(2003)131<2361:TNALAS > 2.0.CO;2.

Smith, B. T., R. L. Thompson, J. S. Grams, C. Broyles, and H. E. Brooks, 2012: Convective modes for significant severe thunderstorms in the contiguous United States. Part I: Storm classification and climatology. Wea. Forecasting, 27, 11141135, https://doi.org/10.1175/WAF-D-11-00115.1.

Thompson, R. L., R. Edwards, J. A. Hart, K. L. Elmore, and P. Markowski, 2003: Close proximity soundings within supercell environments obtained from the Rapid Update Cycle. Wea. Forecasting, 18, 1243-1261, https://doi.org/10.1175/15200434(2003)018<1243:CPSWSE >2.0.CO;2.

, B. T. Smith, J. S. Grams, A. R. Dean, and C. Broyles, 2012: Convective modes for significant severe thunderstorms in the contiguous United States. Part II: Supercell and QLCS tornado environments. Wea. Forecasting, 27, 1136-1154, https://doi.org/ 10.1175/WAF-D-11-00116.1.

Townsend, R. D., and D. R. Johnson, 1985: A diagnostic study of the isentropic zonally averaged mass circulation during the First GARP Global Experiment. J. Atmos. Sci., 42, 1565-1579, https:// doi.org/10.1175/1520-0469(1985)042<1565:ADSOTI>2.0.CO;2. 
Uccellini, L. W., and D. R. Johnson, 1979: The coupling of upper and lower tropospheric jet streaks and implications for the development of severe convective thunderstorms. Mon. Wea. Rev., 107, 682-703, https://doi.org/10.1175/1520-0493(1979) 107<0682:TCOUAL $>2.0$. CO;2.

Velasco, I., and J. M. Fritsch, 1987: Mesoscale convective complexes in the Americas. J. Geophys. Res., 92, 9591-9613, https://doi.org/10.1029/JD092iD08p09591.
Weisman, M. L., and J. B. Klemp, 1982: The dependence of numerically simulated convective thunderstorms on vertical wind shear and buoyancy. Mon. Wea. Rev., 110, 504-520, https://doi. org/10.1175/1520-0493(1982)110<0504:TDONSC >2.0.CO;2.

Zipser, E. J., D. J. Cecil, C. Liu, S. W. Nesbitt, and D. P. Yorty, 2006: Where are the most intense thunderstorms on Earth? Bull. Amer. Meteor. Soc., 87, 1057-1071, https://doi.org/ 10.1175/BAMS-87-8-1057. 